\title{
Fibroblasts direct differentiation of human breast epithelial progenitors
}

\author{
Mikkel Morsing ${ }^{1,2,3}$ (D) Jiyoung Kim ${ }^{1,2}$, René Villadsen ${ }^{1}$, Nadine Goldhammer ${ }^{1,2}$, Abbas Jafari ${ }^{1,2,4}$, \\ Moustapha Kassem ${ }^{1,2,4}$, Ole William Petersen ${ }^{1,2}$ and Lone Rønnov-Jessen ${ }^{5^{*}}$ (i)
}

\begin{abstract}
Background: Breast cancer arises within specific regions in the human breast referred to as the terminal duct lobular units (TDLUs). These are relatively dynamic structures characterized by sex hormone driven cyclic epithelial turnover. TDLUs consist of unique parenchymal entities embedded within a fibroblast-rich lobular stroma. Here, we established and characterized a new human breast lobular fibroblast cell line against its interlobular counterpart with a view to assessing the role of region-specific stromal cues in the control of TDLU dynamics.
\end{abstract}

Methods: Primary lobular and interlobular fibroblasts were transduced to express human telomerase reverse transcriptase (hTERT). Differentiation of the established cell lines along lobular and interlobular pathways was determined by immunocytochemical staining and genome-wide RNA sequencing. Their functional properties were further characterized by analysis of mesenchymal stem cell (MSC) differentiation repertoire in culture and in vivo. The cells' physiological relevance for parenchymal differentiation was examined in heterotypic co-culture with fluorescence-activated cell sorting (FACS)-purified normal breast primary luminal or myoepithelial progenitors. The co-cultures were immunostained for quantitative assessment of epithelial branching morphogenesis, polarization, growth, and luminal epithelial maturation. In extension, myoepithelial progenitors were tested for luminal differentiation capacity in culture and in mouse xenografts. To unravel the significance of transforming growth factor-beta (TGF- $\beta$ )-mediated crosstalk in TDLU-like morphogenesis and differentiation, fibroblasts were incubated with the TGF- $\beta$ signaling inhibitor, SB431542, prior to heterotypic co-culture with luminal cells.

Results: hTERT immortalized fibroblast cell lines retained critical phenotypic traits in culture and linked to primary fibroblasts. Cell culture assays and transplantation to mice showed that the origin of fibroblasts determines TDLUlike and ductal-like differentiation of epithelial progenitors. Whereas lobular fibroblasts supported a high level of branching morphogenesis by luminal cells, interlobular fibroblasts supported ductal-like myoepithelial characteristics. TDLU-like morphogenesis, at least in part, relied on intact TGF- $\beta$ signaling.

Conclusions: The significance of the most prominent cell type in normal breast stroma, the fibroblast, in directing epithelial differentiation is largely unknown. Through establishment of lobular and interlobular fibroblast cell lines, we here demonstrate that epithelial progenitors are submitted to stromal cues for site-specific differentiation. Our findings lend credence to considering stromal subtleties of crucial importance in the development of normal breast and, in turn, breast cancer.

Keywords: Breast, Fibroblast, Epithelial progenitors, Differentiation

\footnotetext{
* Correspondence: Ironnov-jessen@bio.ku.dk

${ }^{5}$ Section for Cell Biology and Physiology, Department of Biology, University of Copenhagen, Copenhagen, Denmark

Full list of author information is available at the end of the article
}

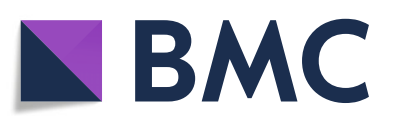

(c) The Author(s). 2020 Open Access This article is licensed under a Creative Commons Attribution 4.0 International License, which permits use, sharing, adaptation, distribution and reproduction in any medium or format, as long as you give appropriate credit to the original author(s) and the source, provide a link to the Creative Commons licence, and indicate if changes were made. The images or other third party material in this article are included in the article's Creative Commons licence, unless indicated otherwise in a credit line to the material. If material is not included in the article's Creative Commons licence and your intended use is not permitted by statutory regulation or exceeds the permitted use, you will need to obtain permission directly from the copyright holder. To view a copy of this licence, visit http://creativecommons.org/licenses/by/4.0/ The Creative Commons Public Domain Dedication waiver (http://creativecommons.org/publicdomain/zero/1.0/) applies to the data made available in this article, unless otherwise stated in a credit line to the data. 


\section{Background}

There is an increasing appreciation that the generic term "fibroblast" is not simply synonymous with any spindleshaped stromal cell type manufacturing an acellular interstitial collagenous tissue. In mice, for example, separate fibroblast lineages govern the papillary and the reticular layers of the dermis [1]. Functionally, these fibroblasts also carry out important different functions related to epidermal and subcutaneous homeostasis, respectively [1]. In human tissue, fibroblasts have attracted most attention in relation to tumor formation. Here, they are referred to as myofibroblasts or cancer-associated fibroblasts (CAFs) and at different times have been considered as either facilitating or inhibiting tumor progression and thus offering potential new avenues of therapeutic intervention [2]. Indeed, mesenchymal cues are considered sufficient to induce malignant transformation [3]. In the human breast, initial transformation is thought to take place in epithelial progenitors residing in so-called terminal duct lobular units (TDLUs [4];). The TDLU is the functional unit of the human breast and consists of a branching terminal duct ending in varying numbers of acinus-like ductules, all of which are embedded in loose connective tissue (reviewed in $[5,6])$. The loose connective tissue is unique for the TDLUs, which drain into the interlobular ducts, which in turn are embedded in a more dense connective tissue (reviewed in [5]). For this reason, several efforts have been made to characterize lobular fibroblasts as a separate lineage with functional properties [7-9]. Recently, we provided unequivocal evidence for the existence of a CD105 ${ }^{\text {high }}$ TDLU-resident lobular fibroblast with properties different from interlobular fibroblasts [10]. While the $\mathrm{CD} 105^{\text {high }}$ lobular fibroblasts resemble mesenchymal stem cells (MSCs) both by phenotype and function, CD26 $6^{\text {high }}$ interlobular cells remain fibroblast restricted [10].

The epithelial compartments of lobules and ducts also differ. Thus, in addition to the obvious morphological difference between the compartments, epithelial progenitors, which differ by cytokeratin expression [11], have been identified in both ducts and TDLUs [12, 13]. Apparently, this difference is preprogrammed in myoepithelial progenitors at the apex of the hierarchy and maintained upon differentiation after several generations in culture and in vivo [11]. In light of the existence of functionally distinct fibroblasts in human skin [14], it is tempting to speculate that myoepithelial differentiation programs, at least in part, are governed by neighboring stromal cells. With the aim of unraveling critical aspects of normal breast development, and, in turn, gain insight into how stromal diversity impinges on epithelium during cancer development, we resolved that access to established fibroblast cell lines would be necessary not least for the sake of reproducibility.
We here embarked with hTERT immortalization of prospectively isolated lobular $\mathrm{CD} 105^{\text {high }}$ and interlobular CD26 ${ }^{\text {high }}$ human breast fibroblasts. We established two different fibroblast cell lines and show that they specifically direct the differentiation of primary epithelial cell progenitors.

\section{Methods}

\section{Tissue}

Normal breast tissue was obtained from women undergoing reduction mammoplasty for cosmetic reasons. Information about donors is restricted to the donor's age at the time of surgery. The tissue was donated with written consent by donors who received information before surgery at a clinic in the Greater Copenhagen area, Denmark. The Regional Scientific Ethical Committees (Region Hovedstaden, H-2-2011-052) and the Danish Data Protection Agency (2011-41-6722) reviewed and approved the use and storage of human material. Some of the donated tissue has been included in other studies. Procedures for orthotopic injection of human cells into the mouse mammary fat pad or under the skin was reviewed and approved by the Danish National Animal Experiment Inspectorate (2017-15-0201-01315 and 2017-15-0201-01210).

\section{Cell isolation and cell culture}

An established protocol for preparation and isolation of stromal cells and epithelial organoids was applied and can be found elsewhere [15]. We used four sets of primary $\mathrm{CD} 105^{\text {high }} / \mathrm{CD} 26^{\text {low }}$ lobular and $\mathrm{CD} 105^{\text {low }} /$ CD26 ${ }^{\text {high }}$ interlobular human breast fibroblastic cells (HBFCs) from four different biopsies obtained from donors at 19, 20, 23, and 29 years of age, which had been isolated previously [10]. These cell strains as well as the two hTERT immortalized fibroblast cell lines (iHBFCs, $\mathrm{iHBFC}^{\mathrm{CD} 105}$ and $\mathrm{iHBFC}^{\mathrm{CD} 26}$, respectively), derived from a donor of the age of 20 years were maintained in DMEM/F-12 (DMEM:Ham's F12 Nutrient Mixture (F12), 1:1 v/v, Life Technologies) supplemented with 5\% fetal bovine serum (FBS, Sigma), $2 \mathrm{mM}$ glutamine, and penicillin-streptomycin antibiotics (DMEM/F12-5\%). The cultures were plated at a density of $5600 \mathrm{cells} / \mathrm{cm}^{2}$ in collagen coated flasks (Nunc, $8 \mu \mathrm{g}$ collagen $/ \mathrm{cm}^{2}$, PureColl, Cell Systems).

An hTERT immortalized MSC line, hMSC-TERT4 [16], referred to here as hMSC-TERT was cultured on plastic (Nunc) in Minimum Essential Medium (MEM, containing Earle's salts and L-Glutamine, Gibco) supplemented with 10\% FBS (South American Origin, Gibco) and $1 \%$ penicillin-streptomycin (Gibco) (MEM-10\%) and split $1: 4$ at $\sim 80 \%$ confluence. All cell cultures were maintained at $37^{\circ} \mathrm{C}$ in a humidified atmosphere with $5 \%$ $\mathrm{CO}_{2}$ with medium change three times a week. 
Population doubling level (PDL) was calculated as follows: $\mathrm{PDL}=3.32(\log I-\log Y)+\mathrm{X}$, where $I$ is the cell number of the inoculum, $Y$ is the cell yield, and $X$ is the population doubling of the inoculum. The hTERT immortalized breast fibroblasts have currently been propagated for more than 80 passages (available through Ximbio, UK, IAHF, cat. no. 153783 and IEHF, cat. no. 153784).

\section{Viral transduction}

Viral constructs used included human telomerase (pBabe-neo-hTERT, Addgene \#1774, a gift from Robert Weinberg [17]), empty vector (pBabe-neo, addgene \# 1767, a gift from Hartmut Land \& Jay Morgenstern \& Robert Weinberg [18]), and viral packaging construct pCL-Ampho (a gift from Dr. Hung Nguyen, Center for Cancer Research, National Cancer Institute, Bethesda, MD, USA [19]).

Retroviral particles +/- the hTERT construct were generated by transient co-transfection of pBabe-neohTERT or pBabe-neo $(5 \mu \mathrm{g})$ and pCL-Ampho $(2.5 \mu \mathrm{g})$ constructs into HEK293T cells grown in collagen coated flasks using the calcium-phosphate method. The following day, the DMEM/F12-5\% medium was replaced. Medium containing viral particles was collected $96 \mathrm{~h}$ post transfection, passed through a $0.45-\mu \mathrm{m}$ filter. Subconfluent fibroblast cultures in passage eight were transduced with the viral supernatant supplemented with $8 \mu \mathrm{g} / \mathrm{mL}$ polybrene at serial dilution overnight upon when the medium was replaced. At $90 \%$ confluency, the transduced cells underwent antibiotic selection with medium containing $300 \mu \mathrm{g} / \mathrm{mL}$ G418 (Life Technologies) for 9 days until non-transduced control cells showed no signs of survival. The concentration of antibiotic used was determined prior to transduction by testing different concentrations of G418 and choosing the dose of $300 \mu \mathrm{g} / \mathrm{mL} \mathrm{G418}$, which eliminated all cells within 1 week. The transduction efficiency was not more than $15 \%$, in which the majority of cells were transduced by one copy of retroviral particle [20].

\section{RNA extraction, RT-qPCR, and next generation sequencing}

To measure hTERT expression, total RNA was extracted from hTERT-transduced HBFCs, iHBFCs, and empty vector- transduced HBFCs, evHBFCs, in passage 11 according to the manufacturer's instructions (Sigma, GenElute, RTN70) and the RNA was reverse transcribed to cDNA using the High Capacity RNA-to-cDNA Kit (Applied Biosystems). Real-time quantitative polymerase chain reaction (RT-qPCR) was performed as described [11] using TaqMan Gene Expression Assays (Applied Biosystems) and the TaqMan primers: human telomerase reverse transcriptase (hTERT, Hs00972656_m1), glyceraldehyde-3-phosphate-dehydrogenase (GAPDH, Hs02758991_g1), hypoxanthine phosphoribosyltransferase 1 (HPRT1, Hs99999909_m1), and phosphoglycerate kinase 1 (PGK1, Hs00943178_g1). Gene expression was determined using the formula $1 /\left(2^{\Delta \mathrm{CT}}\right)$, in which $\Delta \mathrm{CT}$ represents the difference between the target and the geometric mean of reference genes. GAPDH, HPRT1, and PGK1 served as reference genes for normalization.

For next generation sequencing, total RNA was extracted using Trizol (Thermo Fischer) and a spin column method according to the manufacturer's instructions (Zymo Research) from subconfluent duplicate cultures of $\mathrm{HBFC}^{\mathrm{CD} 105}$ and $\mathrm{HBFC}^{\mathrm{CD} 26}$ in passage 9 and from duplicate cultures of passage $24 \mathrm{iHBFC}^{\mathrm{CD} 105}$ and passage $25 \mathrm{iHBFC}^{\mathrm{CD} 26}$. RNA sequencing and bioinformatics analysis was performed by the Beijing Genomics Institute (BGI), Hong Kong, as previously described [11]. In brief, sequencing was performed using BGISeq 500 and $13.7 \mathrm{M}$ clean reads were generated for each sample. Mapped clean reads to reference using Bowtie 2 tool [21] were then used to calculate gene expression with the RSEM package [22]. To identify differentially expressed genes (DEGs) between groups, the DESeq2 method was used [23]. A Venn diagram (https://bioinfogp.cnb.csic.es/tools/venny/index.html) was used to depict the overlap of DEGs with a 2-fold difference between fibroblast populations.

For analysis of cluster of differentiation (CD) molecular signature, a comprehensive list of 453 unique $C D$ molecules and their gene names was retrieved from the Uniprot database (https://www.uniprot.org/docs/cdlist) and applied to filter DEGs with a 2-fold difference and FPKM larger than 5. The R software (v3.2.2) was used to plot gene expression values in a heatmap.

\section{Adipocyte and osteoblast differentiation}

To assess adipogenic differentiation, in seven independent tests, iHBFCs in passages $27,28,40,49$, and 50 were plated at 40,000 cells $/ \mathrm{cm}^{2}$ in DMEM/F12-5\%. One to two days after plating, the medium was changed to adipogenic inducing medium (MEM-10\% with 2.5\% horse serum (Sigma Aldrich), $100 \mathrm{nM}$ dexamethasone (SigmaAldrich), $500 \mu \mathrm{M}$ 1-methyl-3-isobutylxanthine (IBMX, Sigma-Aldrich), $1 \mu \mathrm{M}$ rosiglitazone (BRL49653, Cayman Chemical), and $5 \mu \mathrm{g} / \mathrm{mL}$ insulin (Sigma-Aldrich)) [24]. Controls received MEM-10\% medium. The medium was replaced three times per week over 13-25 days on which the cultures were evaluated by Oil Red O staining [25]. Nuclei were counterstained by hematoxylin and photographs were acquired on Leica DM5500B. For osteogenic differentiation, in 5 independent tests, HBFCs in passage $22,28,35,49$, and 50 were plated overnight at 20,000 cells $/ \mathrm{cm}^{2}$ and were then exposed to osteogenic inducing medium (MEM-10\% supplemented with 10 
$\mathrm{mM} \beta$-glycerophosphate (Calbiochem), $50 \mu \mathrm{g} / \mathrm{mL} \mathrm{L-as-}$ corbic acid (Sigma), $10 \mathrm{nM}$ dexamethasone (Sigma), and $10 \mathrm{nM}$ 1,25-dihydroxy vitamin D3 (LEO Pharma) [26] for 28-32 days with medium change three times a week. Controls received MEM-10\% medium. Mineralization was assessed by alizarin red staining [24] and photographs were acquired with Leica Z6 AP0.

\section{Fluorescence-activated cell sorting and co-cultures}

Primary MUC1 $1^{\text {high }}$ luminal epithelial cells $\left(\mathrm{CD} 271^{\text {low }} /\right.$ $\left.\mathrm{MUC1}^{\text {high }}\right)$ and $\mathrm{CD} 271^{\text {high }}$ myoepithelial cells $\left(\mathrm{CD} 271^{\text {high }} / \mathrm{MUC}^{\text {low }}\right.$ or $\left.\mathrm{CD} 271^{\text {high }} / \mathrm{EpCAM}^{\text {low }}\right)$ were isolated from breast tissue biopsies as described $[10,11]$. Freshly isolated myoepithelial cells were plated (2500$5000 \mathrm{cells} / \mathrm{cm}^{2}$ ) onto confluent fibroblasts feeder layers of $\mathrm{iHBFC}^{\mathrm{CD} 105}$ and $\mathrm{iHBFC}{ }^{\mathrm{CD} 26}$, respectively. Myoepithelial/fibroblast co-cultures were maintained in a specialized culture medium, Myo medium [11], supplemented with 5\% FBS (Myo 5\%). In one experiment, cultures were maintained in DMEM/F12-5\%, which gave a similar result. Primary myoepithelial cells were also plated on collagen coated plastic in Myo medium and expanded to passage 2 before use in co-cultures with fibroblasts in passage 3 using Myo 5\% medium.

To isolate myoepithelial cells from co-cultures, the cell cultures were trypsinized ( $0.25 \%$ trypsin/1 mM EDTA), counted using a Burker-Türk chamber and stained for CD271-APC at $4{ }^{\circ} \mathrm{C}$ for $30 \mathrm{~min}$ followed by two washes in HEPES/BSA/EDTA buffer. Fixable Viability Stain 780 (1:1000, BD Biosciences) live-dead discriminator was added prior to analysis and sorting on FACS ARIA-II or FACS Fusion (BD Biosciences). FACS data analysis was performed with FACS DIVA and FlowJo software.

In a cross-over test, myoepithelial cells in primary culture were isolated from co-cultures with $\mathrm{iHBFC}^{\mathrm{CD} 105}$ and $\mathrm{iHBFC}^{\mathrm{CD} 26}$, respectively, and from each, 1600 myoepithelial cells $/ \mathrm{cm}^{2}$ were re-plated onto confluent fibroblast feeders of both $\mathrm{iHBFC}^{\mathrm{CD} 105}$ and $\mathrm{iHBFC}^{\mathrm{CD} 26}$. To account for variance in absolute CD271 levels and for normalization purposes, myoepithelial CD271 levels were divided by the mean background CD271 fluorescence of the co-cultured fibroblasts.

For assessment of epithelial morphogenesis, FACS sorted primary MUC1 $1^{\text {high }}$ luminal cells $\left(6000\right.$ cells $\left./ \mathrm{cm}^{2}\right)$ were seeded in Myo medium onto confluent feeder layers of iHBFCs and observed for up to 3 weeks using a phase contrast microscope and imaged (Leica DM IL).

In 15 tests using TGF- $\beta$ signaling inhibition by SB431542 (Axon 1661, Axon Medchem), HBFCs representing four biopsies were allowed to grow to confluence over 7 days and were then treated with $10 \mu \mathrm{M}$ SB431542 for 3 days before plating of MUC1 ${ }^{\text {high }}$ luminal cells at day 10 from five biopsies.
In two tests, MUC1 ${ }^{\text {high }}$ luminal cells from two biopsies were plated onto confluent HBFCs from two biopsies in Myo medium. From days 2-9, the co-cultures were exposed to $10 \mu \mathrm{M} \mathrm{SB} 431542$ or vehicle (DMSO).

\section{Luminal differentiation}

To assess the ability of fibroblasts to direct luminal differentiation capacity of myoepithelial progenitors, fourteen myoepithelial/fibroblast co-cultures (7 pairs of $\mathrm{iHBFC}^{\mathrm{CD} 105}$ and $\mathrm{iHBFC}^{\mathrm{CD} 26}$ ) representing six different biopsies were used. Specifically, from a pair of cocultures in DMEM/F12-5\% (passage 1) and three coculture pairs in Myo 5\% medium (passages 1, 2 and 3), representing three different biopsies, CD271 ${ }^{\text {high }}$ myoepithelial cells were isolated by FACS and plated at 1600 cells $/ \mathrm{cm}^{2}$ for analysis of luminal differentiation. In three other experiments, representing three additional biopsies, primary co-cultures from Myo 5\% medium were trypsinized and cells plated without prior FACS sorting into luminal differentiation conditions. For luminal differentiation, conditions were used as described [11], or in some experiments, with similar results, the culture medium was replaced with DMEM/F12 supplemented with $2 \mathrm{mM}$ glutamine, $50 \mu \mathrm{g} / \mathrm{mL}$ gentamycin (Biological Industries), $0.5 \mu \mathrm{g} / \mathrm{mL}$ hydrocortisone (Sigma, $\mathrm{H} 0888$ ), $5 \mu \mathrm{g} / \mathrm{mL}$ insulin (Sigma, I6634), $30 \mathrm{ng} / \mathrm{ml}$ epidermal growth factor (recombinant human) (Peprotech), 0.4\% (approx. $50 \mu \mathrm{g} / \mathrm{mL}$ ) bovine pituitary extract (Gibco, 13-028-014), $20 \mathrm{ng} / \mathrm{mL}$ basic fibroblast growth factor (Peprotech), $25 \mu \mathrm{M}$ Repsox (Sigma, R0158), $4 \mu \mathrm{g} / \mathrm{mL}$ heparin (Sigma), and $20 \mu \mathrm{L} / \mathrm{mL}$ B27 (Life Technologies).

\section{Immunohistochemistry and immunocytochemistry}

Cryostat sections of normal breast tissue biopsies and xenografts as well as cultured cells and cell smears were stained essentially as previously described after fixation in either methanol ( $\mathrm{M}$ in Table 1) or formaldehyde ( $\mathrm{F} 1$ in Table 1) or formaldehyde followed by methanol to acetone (F2 in Table 1) and included controls without primary antibody [12, 27, 28]. Blocking was performed for $5 \mathrm{~min}$ in $10 \%$ goat serum in PBS or Ultra V Block (Lab Vision Corporation TA125-UB). Cells were incubated with primary and secondary antibodies for 60 and 30 min respectively (Table 1 ). For immunoperoxidase staining, the secondary antibody was UltraVision ONE HRP Polymer (Thermo Fisher, TL-125-PHJ), and for fluorescence, isotype-specific goat anti-mouse IgG AlexaFluor (AF, Life Technologies) secondary antibodies were used. Nuclei of immunoperoxidase- or fluorescence-stained sections and cells were counterstained with hematoxylin or ProLong Gold Antifade reagent with 4,6-diamino-2-phenylindole (DAPI, Life Technologies), respectively. 
Table 1 List of antibodies and protocols

\begin{tabular}{|c|c|c|c|c|c|c|}
\hline Antibody & Clone/isotype & Company/catalog no & Peroxidase & Fluorescence & FACS & Fixation \\
\hline a-SMA & 1A4 & Sigma/A2547 & & $1: 5000$ & & F1 \\
\hline CD105 & SN6 & Abcam/Ab11414 & 1:200 & & & $F 2 / M$ \\
\hline CD26 & $202-36$ & Abcam/Ab3154 & $1: 50$ & & & F2/M \\
\hline CD140b & PR7212 & R\&D Systems/MAB1263 & $1: 1000-1: 2000$ & & & F1 \\
\hline CD248 & EPR17081 & Abcam/ab204914 & $1: 1000-1: 2500$ & & & F1 \\
\hline K17 & E3 & DAKO/M7046 & & $1: 50$ & & $\mathrm{~F} 1 / \mathrm{F} 2 / \mathrm{M}$ \\
\hline K14 & LL002 & Monosan/MONX10687 & & $1: 25-1: 50$ & & $\mathrm{~F} 1 / \mathrm{F} 2 / \mathrm{M}$ \\
\hline K19 & Ba16 & GenWay/GWB22664E & 1:200 & & & F2/M \\
\hline K19 & Ba16 & Abcam/ab20210 & 1:200 & $1: 50$ & & F2/M \\
\hline K19 & A53-B/A2 & Abcam/ab7754 & & $1: 100$ & & $\mathrm{~F} / \mathrm{M}$ \\
\hline CD271 & ME20.4 & BioLegend/345102 & & $1: 25$ & & F1 \\
\hline CD271-APC & ME20.4 & Cedarlane/CL10013APC & & & $1: 50$ & \\
\hline CD326-488 & $9 C 4$ & BioLegend/324210 & & & $1: 50$ & \\
\hline CD326 & $9 C 4$ & BioLegend/324202 & & $1: 25$ & & F1 \\
\hline MUC1 & 115D8 & Biogenesis/1510-5025 & & 1:10-1:20 & $1: 50$ & F2 \\
\hline Vimentin & SP20 & Thermo Fisher Scientific/RM-9120 & $1: 200$ & & & F1 \\
\hline AF488 & $\lg \mathrm{g} 1$ & Life Technologies/A21121 & & $1: 500$ & & \\
\hline AF488 & $\operatorname{lgG} 2 \mathrm{~b}$ & Life Technologies/A21141 & & $1: 500$ & $1: 500$ & \\
\hline AF488 & $\operatorname{lgG} 3$ & Life Technologies/A21151 & & $1: 500$ & & \\
\hline AF568 & $\lg G 1$ & Life Technologies/A21124 & & $1: 500$ & & \\
\hline AF568 & $\lg G 2 b$ & Life Technologies/A21144 & & $1: 500$ & & \\
\hline AF647 & $\lg G 2 a$ & Life Technologies/A21241 & & $1: 500$ & & \\
\hline
\end{tabular}

Eleven pairs of $\mathrm{iHBFC} \mathrm{CD}^{\mathrm{CD} 105}$ and $\mathrm{iHBFC}{ }^{\mathrm{CD} 26}$ spanning passages 11-50 were stained by immunoperoxidase for CD105 (Abcam, SN6) and CD26 (Abcam, 202-36). Photographs were acquired with Leica DM5500B.

Six to eight micrometers of cryostat sections of three different biopsies were triple-stained by fluorescence for CD271 (BioLegend, ME20.4), $\alpha$-SMA (Sigma, 1A4), and EpCAM (BioLegend, 9C4) followed by AF488 (IgG1), AF568 (IgG2b), and AF647 (IgG2a). The triple-stainings were evaluated and imaged using confocal microscopy (Zeiss LSM 700).

Six to eight micrometers of cryostat sections of 10 different biopsies were immunoperoxidase-stained for CD140b (PDGFR $\beta$; R\&D Systems, PR7212) and CD248 (Abcam, EPR17081), evaluated and imaged (DM5500B).

Xenografts were sectioned $(6-8 \mu \mathrm{m})$ and co-stained by fluorescence for K19 (Abcam, A53-B/A2) and K14 (Monosan, LL002), followed by incubation with AF568 (IgG2a) and AF488 (IgG3).

MUC1 ${ }^{\text {high }}$-luminal/fibroblast co-cultures were immunoperoxidase-stained on days 9-12 for Keratin 19 (GenWay or abcam, BA16) and images acquired on Leica Z6 AP0 at 1.25 magnification. The images were analyzed with ImageJ software (v1.52a) in batch mode using a macro previously established [10] counting the number of epithelial structures larger than $0.0026 \mathrm{~mm}^{2}$.

For observation of epithelial polarization, 10 pairs of $\mathrm{iHBFC}^{\mathrm{CD} 105}$ and $\mathrm{iHBFC}^{\mathrm{CD} 26}$ in co-culture with luminal epithelial cells from five different biopsies were costained on days 9-23 by fluorescence for K19 (Abcam, BA16) and MUC1 (Biogenesis, 115D8) followed by AF488 (IgG2b) and AF568 (IgG1). The co-stainings were evaluated by epi-fluorescence microscopy (Leica DM5500B) and imaged using confocal microscopy (Zeiss LSM 700).

Myoepithelial/fibroblast co-cultures were co-stained for K14 (Monosan, LL002), K17 (Dako, E3) and K19 (Abcam, BA16), followed by AF488 (IgG3), AF568 (IgG2b) and AF568 (IgG1). Images of three cocultures representing three different biopsies were acquired with Leica DM5500B and K17 intensity measured with image analysis software, ImageJ (1.52a). For this, segmentation was first performed on K14 using the ImageJ functions Multiply, Median, and Make Binary providing the outline of the myoepithelial cells. This segmentation was then applied to corresponding images of $\mathrm{K} 17$ in which fluorescence intensity was measured. 
Cultures subjected to luminal differentiation conditions were stained for K19 (Abcam, BA16) by immunoperoxidase on days $8-12$, evaluated and imaged using Leica DM5500B.

For a quantitative assessment of CD271 as a marker for ductal myoepithelium, cellular smears were prepared from FACS-isolated CD271 $1^{\text {high }}$ versus CD271 ${ }^{\text {low }}$ myoepithelial cells from four different biopsies. The smeared cells were fixed at room temperature for $10 \mathrm{~min}$ in 3.7\% paraformaldehyde, washed three times in PBS, and permeabilized in $0.01 \%$ Triton X-100 for $10 \mathrm{~min}$ followed by three washes in PBS. The fixed smears were blocked by $5 \mathrm{~min}$ incubation in Ultra V Block followed by $5 \mathrm{~min}$ in $10 \%$ goat serum before staining with K17 (Dako, E3) antibody, followed by AF488 (IgG2b) and DAPI. Images of stained smears were acquired with Leica DM5500B and a minimum 100 cells per cell preparation was counted using ImageJ (v1.52a) Cell Counter plugin.

Xenografts were sectioned $(6-8 \mu \mathrm{m})$ and co-stained by fluorescence for K19 (Abcam, A53-B/A2) and K14 (Monosan, LL002), followed by incubation with AF568 (IgG2a) and AF488 (IgG3) prior to confocal imaging (Zeiss LSM 700).

\section{In vivo bone formation assay}

One million hMSC-TERT ( 2 implants, 1 mouse) and iHBFC $^{\mathrm{CD} 105}$ (4 implants, 3 mice) were mixed with $40 \mathrm{mg}$ hydroxyapatite/tricalcium phosphate (HA/TCP) ceramic powder (Zimmer Scandinavia, Albertslund, Denmark), incubated at $37^{\circ} \mathrm{C}$ at $5 \% \mathrm{CO}_{2}$ atmosphere overnight and then implanted subcutaneously in the dorsal side of NOD.CB17-Prkdc ${ }^{\text {Scid } / J}$ mice (Charles River, France) [29]. Implants were removed after 8 weeks, transferred to $4 \%$ neutral buffered formalin for $24 \mathrm{~h}$ followed by incubation in formic acid for 3 days. The processed implants were paraffin-embedded, sectioned, and stained as described [30] with human-specific vimentin (Thermo Fisher Scientific, clone SP20) antibody or by hematoxylin-eosin [31].

\section{In vivo morphogenesis}

From primary co-culture with $\mathrm{iHBFC}^{\mathrm{CD} 105}$ or

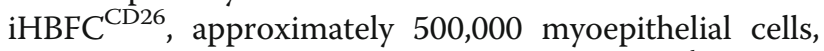
with or without removal of co-cultured $\mathrm{CD} 271^{\text {low }}$ fibroblasts by FACS, representing two biopsies, were admixed with 125,000 or 500,000 irradiated $(\sim 20$ Gy $)$ $\mathrm{iHBFC}^{\mathrm{CD} 105}$ or $\mathrm{iHBFC}^{\mathrm{CD} 26}$ cells and suspended in cold 1:1 collagen gel to growth factor reduced Matrigel (BD Biosciences) for transplantation. Cells were orthotopically injected into the 4th left and right mammary fat pad of 7-10-week-old female NOD.Cg-Prkdc ${ }^{\text {SCID }}$ Il2 $\mathrm{rg}^{\text {tm } 1 \text { sug }}$ mice (NOG mice, Taconic) (iHBFC ${ }^{\mathrm{CD} 105}: 10$ transplants, 5 mice; iHBFC ${ }^{\mathrm{CD} 26}: 8$ transplants, 4 mice).
Mice were supplemented with $0.67 \mu \mathrm{g} / \mathrm{mL} 17 \beta$-estradiol (Sigma-Aldrich) in the drinking water throughout the experimental period. After 8 weeks, the mice were sacrificed and the mammary glands excised and snap frozen in $-80^{\circ} \mathrm{C} n$-Hexane (Sigma) before mounting for cryostat sectioning.

\section{Statistics}

Statistical analyses and data visualization were performed with a statistical programing language $\mathrm{R}$ (version 3.6.3) and its integrated development environment, $R$ studio (version 1.2.5033) and GraphPad Prism (version 8). Estimated $p$ values were based on Shapiro-Wilk test for normality, one-way analysis of variance (ANOVA) with Tukey's test, Kruskal-Wallis rank-sum test, Wilcoxon signed-rank test, or nested $t$ test, as indicated.

\section{Results}

Immortalization of human breast fibroblastic cells (HBFCs) We previously purified fibroblasts from reduction mammoplasty specimens and sorted them into lobular $\mathrm{CD} 105^{\text {high }} / \mathrm{CD} 26^{\text {low }}$ and interlobular CD $105^{\text {low }} / \mathrm{CD} 26^{\text {high }}$ lineages which could be propagated in culture [10]. Under these conditions, HBFCs senesce after more than 80 days and approximately 16 passages [10]. To generate lines of HBFCs, we here examined whether retroviral transduction with the hTERT gene would render HBFCs immortal. HBFCs in passage eight were infected with retrovirus encoding hTERT together with a neomycin drug resistance marker or an empty vector. Whereas the empty vector cells did not exhibit extended lifespan over what is expected for HBFCs, the hTERT transduced cells generated populations of infected HBFCs with no significant growth arrest and an apparent infinite life span (Fig. 1a and Additional file Fig. 1). Interestingly, the $\mathrm{CD} 105^{\text {high }}$ - and $\mathrm{CD} 26^{\text {high }}$-derived cell lines given identical growth conditions, stably exhibited different growth properties (Fig. 1a), and have currently been grown for more than 80 passages. Thus, immortalization was successful, and in the following, we refer to the hTERT transduced breast fibroblasts as iHBFC ${ }^{\mathrm{CD} 105}$ and $\mathrm{iHBFC}^{\mathrm{CD} 26}$, respectively.

\section{Differentiation state of iHBFCs}

To characterize the hTERT immortalized lines, we first examined their staining pattern with CD105 and CD26. As seen in Fig. 1b, iHBFC ${ }^{\mathrm{CD} 105}$ and $\mathrm{iHBFC}^{\mathrm{CD} 26}$ maintain high expression of $\mathrm{CD} 105$ and $\mathrm{CD} 26$, respectively (Fig. 1b). In order to further investigate the differences between the two cell lines and in parallel the finite lifespan HBFCs, we next examined the mRNA expression profiles of the $\mathrm{iHBFC}^{\mathrm{CD} 105}$ and $\mathrm{iHBFC}^{\mathrm{CD} 26}$. We found that there were approximately $850-900$ transcripts in each population that were $>2$-fold differentially 


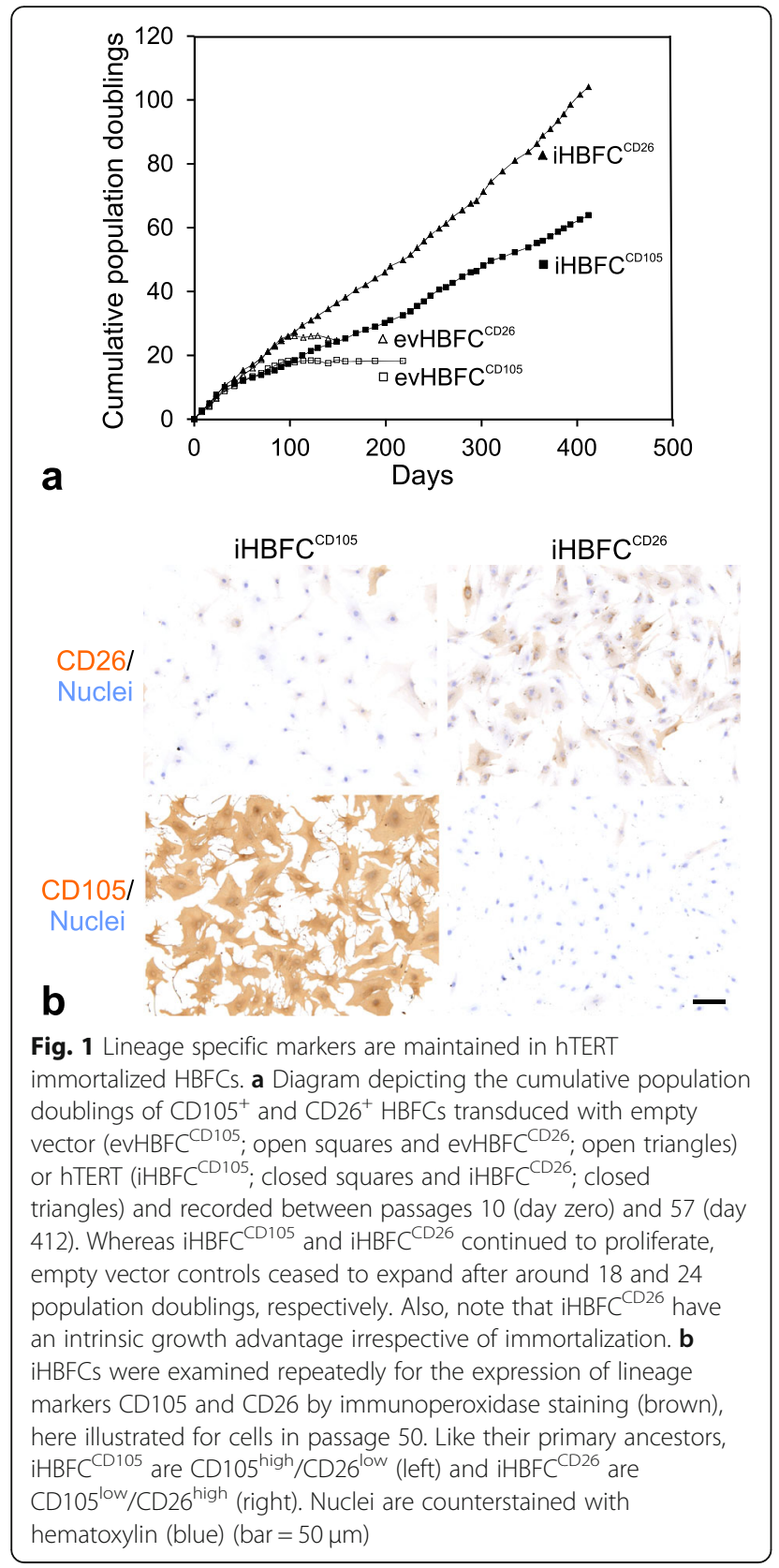

expressed compared to the other population and that in general, the iHBFCs remained well differentiated along lobular- and interlobular-fibroblastic pathways, respectively (Fig. 2a). Thus, in contrast to previous attempts to culture and maintain lobular and interlobular breast fibroblast $[8,9]$ and dermal fibroblast subpopulations [14], the lineages in the present study remain phenotypically distinct in extended culture and upon immortalization.

Since multiple fibroblast subpopulations have been characterized in human dermis based on expression of different combinations of cluster of differentiation (CD) genes [14], we next specifically extracted this information from the mRNA arrays of the iHBFCs (Fig. 2b). The list of 34 genes contained several wellknown fibroblast markers, including CD248 (endosialin/ TEM1, [32]), CD36 (scavenger receptor class B member 3, SCARB3, [33]), CD34 [34], CD140b (platelet-derived growth factor receptor-beta, PDGFR $\beta$ [35];), CD138 (syndecan-1, [36]), CD90 (Thy-1, reviewed in [37]), and CD13 (aminopeptidase N, ANPEP, [8, 38]). Among these, CD90 and CD140b have been defined as panfibroblast markers, which are genes expressed at a high level in both papillary and reticular dermal fibroblasts and all cultured fibroblast lines [14]. In the present study, however, the expression levels of these markers appear to distinguish lobular and interlobular iHBFCs, since $\mathrm{CD} 140 \mathrm{~b}$ is expressed at a higher level in the former, and CD90 is expressed at a higher level in the latter (Fig. 2b). Upon further comparison with human dermis, the most obvious equivalent expressing CD26 is the papillary fibroblast, while CD105 expression concurs with CD36, which is expressed in both lobular breast fibroblasts and lower reticular dermis [39]. Indeed, the iHBFCs serve as a sensible model with relevance to the in vivo setting, which was further illustrated in a series of 10 specimens, where, in addition to CD26 and CD105, two of the identified markers of iHBFCs, CD140b and CD248, recognize the cells in situ which they are supposed to represent (Fig. 2c). This pattern was observed in $8 / 10$ cases. In $2 / 10$ cases, no difference in staining was observed between lobular and interlobular stroma.

Next, we analyzed whether the two cell lineages had also retained critical functional properties in spite of immortality. We have previously shown that CD105 $5^{\text {high }}$ as opposed to CD26 ${ }^{\text {high }}$ HBFCs in several respects behave like MSCs [10]. Here, we conducted a series of experiments between passage 22 and passage 50 to reveal the potential of the iHBFCs with respect to functional differentiation towards adipocyte and osteoblast lineages. Indeed, the iHBFCs remained discernably stable for the entire culture period with respect to their differentiation potential as demonstrated by accumulation of lipid droplets in adipogenic cultures and formation of mineralized matrix in osteoblastic cultures of iHBFC ${ }^{\mathrm{CD} 105}$ only (Additional file Fig. 2a and b). Also in this respect, $\mathrm{iHBFC}^{\mathrm{CD} 105}$ show similarity to reticular fibroblasts, which readily undergo adipogenic differentiation [39]. $\mathrm{iHBFC}^{\mathrm{CD} 105}$ do not, however, exhibit the entire differentiation repertoire of MSCs, since they differ from bone marrowderived MSCs by lack of ability to form bone in vivo (Additional file Fig. 2c). Hence, the iHBFC ${ }^{\mathrm{CD} 105}$ and $\mathrm{iHBFC}^{\mathrm{CD} 26}$ retain critical properties of primary cells and of their putative cells of origin and share lineage relationships with fibroblasts from other tissues. 


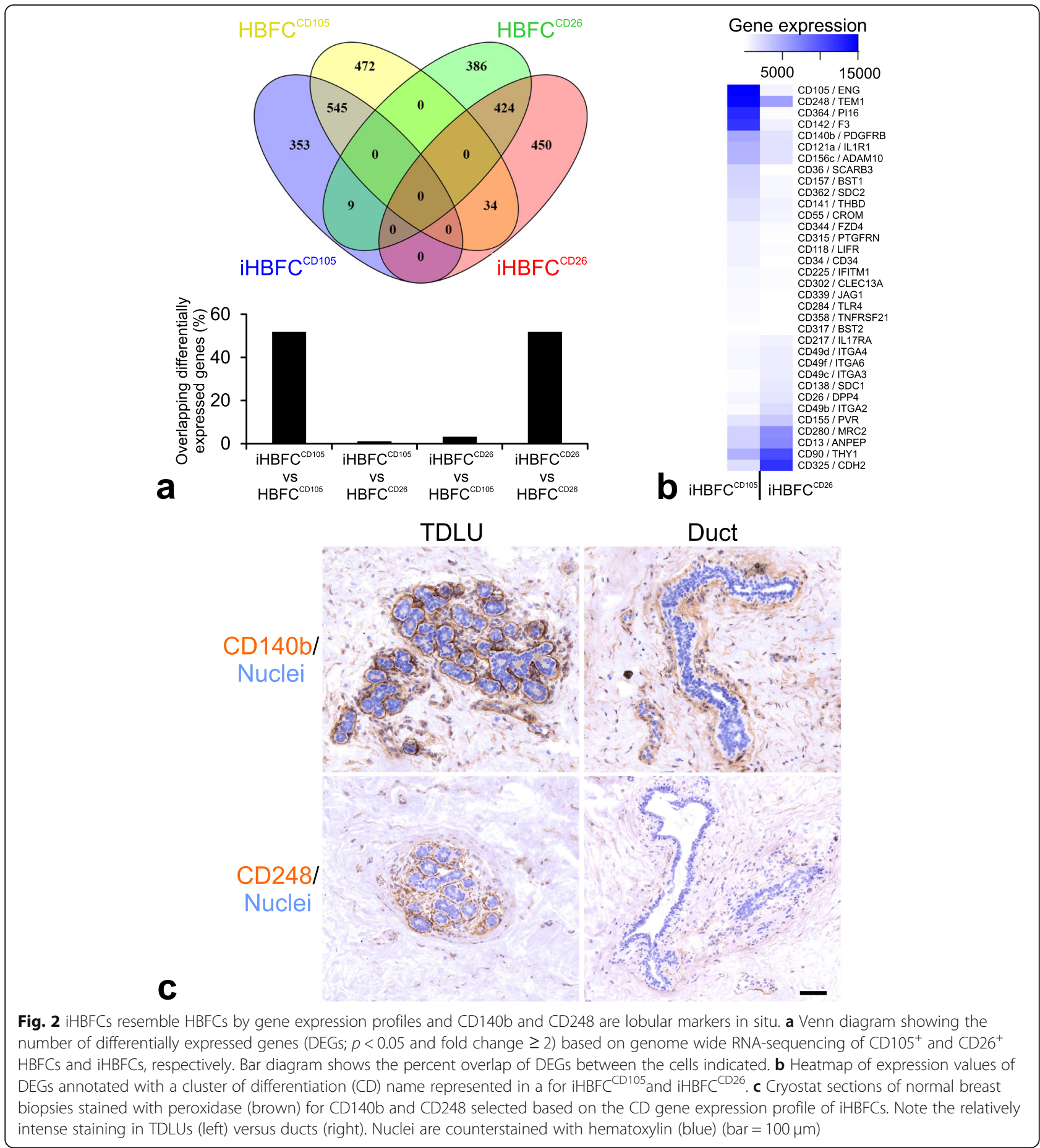

\section{Fibroblast cell type and impact on breast epithelial progenitors}

With a reproducible source of lobular- and interlobularlike HBFCs in hand, we assessed their impact on the neighboring breast epithelium. Firstly, we looked at the luminal epithelial compartment characterized by a high cellular turnover in vivo [12]. Here, we took advantage of a heterotypic co-culture assay designed for measuring branching morphogenesis $[10,40]$. As seen in Fig. 3, the readout from this assay was an unequivocal high level of branching morphogenesis supported by iHBFC ${ }^{\mathrm{CD} 105}$. This difference between $\mathrm{iHBFC}^{\mathrm{CD} 105}$ and $\mathrm{iHBFC}^{\mathrm{CD} 26}$ in inductive capacity was robust throughout the entire culture period from passages 14 to 47 and was independent of source of epithelial cells (Fig. 3). Secondly, we looked at the myoepithelial compartment, which is believed to 


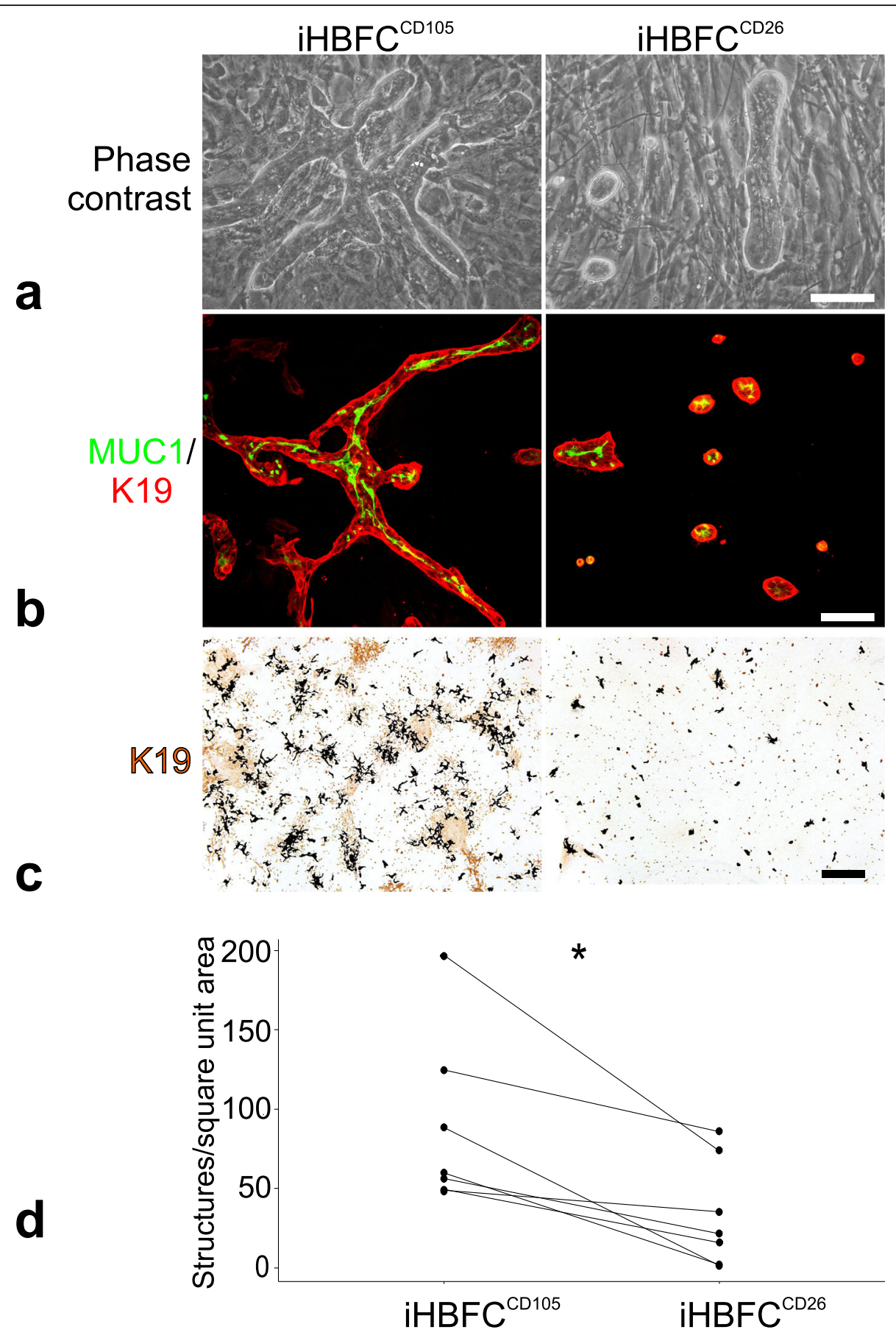

Fig. 3 iHBFC ${ }^{\mathrm{CD} 105}$ support luminal epithelial growth and TDLU-like branching morphogenesis. Comparison of the capacity of $\mathrm{iHBFC} \mathrm{C}^{\mathrm{CD} 105}$ and $\mathrm{iHBFC}^{\mathrm{CD} 26}$ to induce human breast epithelial morphogenesis. a Phase contrast micrographs of luminal breast epithelial cells co-cultured for 16 days on passage $40 \mathrm{iHBFC}^{\mathrm{CD} 105}$ (left) or $\mathrm{HHBFC}^{\mathrm{CD} 26}$ (right) (bar = $100 \mu \mathrm{m}$ ). Only iHBFC ${ }^{\mathrm{CD} 105}$ facilitate elaborate TDLU-like branching morphogenesis. b Double immunofluorescence staining of luminal epithelial/iHBFC co-cultures with K19 (red) and MUC1 (green; bar = $100 \mu \mathrm{m}$ ). Note the staining of correctly polarized MUC1 in $\mathrm{K}_{19}{ }^{+}$structures in both co-cultures. $\mathbf{c}$ Illustration of difference in induced branching morphogenesis by iHBFC $\mathrm{CD}^{\mathrm{CD}} 105$ and $\mathrm{HBFC}^{\mathrm{CD} 26}$, respectively, by low magnification imaging and segmentation in ImageJ of branching morphogenesis in luminal epithelial/iHBFC co-cultures stained by peroxidase for K19 (brown). Segmented images show epithelial structures projected in black pixels (bar $=1000 \mu \mathrm{m})$. $\mathbf{d}$ Dot plot depicting the inductive capacity of seven pairs of $\mathrm{iHBFC}^{\mathrm{CD} 105}$ (left) and $\mathrm{HHBFC}^{\mathrm{CD} 26}$ (right) measured as the number of luminal epithelial structures per square unit area using luminal epithelial cells from five different biopsies. Consistently, iHBFC ${ }^{\mathrm{CD} 105}$ have higher inductive capacity (asterisk indicates significance at $p<0.05$ by Wilcoxon signed-rank test) 
contain the apical-most progenitors in the human breast hierarchy [41-43]. Here, we took advantage of the fact that ductal and lobular myoepithelial cells in situ differ in both their marker expression and their differentiation potential [11]. The question remains as to whether these properties to some extent rely on topographical conditions such as those determined by the adjacent fibroblasts. To address this, we isolated the entire complement of myoepithelial cells from three different biopsies by a CD271 FACS protocol. These myoepithelial cells were plated directly on either iHBFC ${ }^{\mathrm{CD} 26}$ or $\mathrm{iHBFC}^{\mathrm{CD} 105}$ and cultured for 1 week followed by staining for keratin K17 (Fig. 4a) and CD271 (Fig. 4b). Notably, the readout for ductal-like myoepithelial differentiation was based on both high CD271 and high keratin $\mathrm{K} 17$ since these co-segregated in FACS and stainings (Additional file Fig. 3). Interestingly, ductal-like, high expression of both CD271 and K17 entirely relied on coculture with $\mathrm{iHBFC}^{\mathrm{CD} 26}$. That fibroblasts indeed influence epithelial differentiation was further substantiated by passaging the cells to a second passage with switching of the feeders. Now, those myoepithelial cells that were initially ductal-like in phenotype with high CD271 expression became lobular-like with reduced CD271 expression and vice versa (Fig. 4c). This indicates that the myoepithelial phenotype is regulated by surrounding fibroblasts.

Whether this also applies to the next level of differentiation potential of myoepithelial cells, i.e., generation of luminal cells, was examined by measuring the pattern of induced luminal keratin K19 in myoepithelial progenitors under differentiating conditions. Whereas lobularlike luminal differentiation is characterized by emergence of scattered heterogeneous islets of K19-positive luminal cells, ductal-like luminal differentiation entails homogeneous islets reminiscent of their differentiation in vivo [11]. Accordingly, myoepithelial cells primed by co-culture with either iHBFC ${ }^{\mathrm{CD} 105}$ or $\mathrm{iHBFC}^{\mathrm{CD} 26}$ were plated at clonal density under identical luminal differentiation conditions without fibroblast feeders [11]. Based on experiments with 6 different biopsies we found that priming with either iHBFC ${ }^{\mathrm{CD} 105}$ or iHBFC ${ }^{\mathrm{CD} 26}$ impacted on the following luminal differentiation potential corresponding to preferentially scattered or homogeneous keratin K19 staining, respectively (Fig. 5a). This observation was further validated in vivo. Myoepithelial cells primed in co-culture with either ${ }^{\mathrm{iHBFC}} \mathrm{CD}^{\mathrm{C} 105}$ or $\mathrm{iHBFC}^{\mathrm{CD} 26}$ orthotopically injected into NOG mice resulted in bilayered epithelial structures from both origins in $6 / 10$ and $5 / 8$ transplants, respectively. However, while iHBFC $^{\mathrm{CD} 105}$ co-culture- derived myoepithelial cells gave rise to $\mathrm{K}_{1} 4^{- \text {low }} / \mathrm{K} 19^{+}$cells, $\mathrm{iHBFC}^{\mathrm{CD} 26}$ co-culturederived myoepithelial cells gave rise to $\mathrm{K}_{14}{ }^{+} / \mathrm{K} 19^{+} \mathrm{lu}$ minal cells (Fig. 5b). Taken together, these results imply that fibroblasts influence epithelial progenitors and that lobular fibroblasts support the development of a more mature luminal phenotype characteristic of TDLU.

\section{Interruption of a TGF- $\beta$ signaling cascade in $\mathrm{HBFC} \mathrm{C}^{\mathrm{CD} 105}$ and control of epithelial progenitors}

Since lobular fibroblasts exhibit a TGF- $\beta$ signaling signature [10] and CD105 is a co-receptor for TGF- $\beta$ (reviewed in [44]), we speculated whether the TGF- $\beta$ signaling pathway plays a role in the crosstalk between fibroblasts and epithelial progenitors. To explore this, we used the quantitative morphogenesis assay described above and initially incubated luminal epithelial-fibroblast co-cultures directly with the small molecule TGF- $\beta$ signaling inhibitor, SB431542, previously shown by others to impinge on CD105 signaling [45]. Indeed, in 2 out of 2 tests, the number of epithelial structures in $\mathrm{HBFC}^{\mathrm{CD} 105}$, but not in HBFC ${ }^{\mathrm{CD} 26}$ co-cultures, was reduced by treatment with SB431542 (Additional file Fig. 4). To exclusively target the fibroblasts, we then incubated confluent fibroblast feeders with SB431542 for 3 days prior to plating of the luminal cells on top. Disruption of TGF- $\beta$ signaling significantly reduced epithelial structure formation in $\mathrm{HBFC}^{\mathrm{CD} 105}$ co-cultures, but not in HBFC ${ }^{\mathrm{CD} 26}$ co-cultures (Fig. 6). This result suggests that intact TGF- $\beta$ signaling in lobular fibroblasts is instrumental in modulating parenchymal cells.

\section{Discussion}

A number of contextual signals have been implicated in the maintenance of tissue homeostasis in the human breast some of which originating from neighboring fibroblasts and impacting on stem cell behavior (reviewed in [46]). Also, it has long been suspected that fibroblasts exhibit functional specialization according to their anatomical location $[9,47,48]$, but it still remains an open question which cells identify the stromal microenvironment, and how they are specified for the production of proliferation and differentiation cues [46]. Our research in adult breast tissue has revealed the existence of two distinct lineages-a lobular and an interlobular which remain inherently functionally distinct [10]. Here, using hTERT expression vectors, we have been able to generate two populations of cells that reside stably in the lobular-like and interlobular-like states, respectively, as defined by a number of properties including the CD105 and CD26 expression. The resulting fibroblast cell lines are faithful to their identity corresponding to their anatomical site of origin, and specifically, lobular-like fibroblasts, relying on a TGF- $\beta$ signaling pathway, govern epithelial morphogenesis and differentiation typical of the TDLU.

The above observations leave several questions unanswered about the role of fibroblasts in the human 

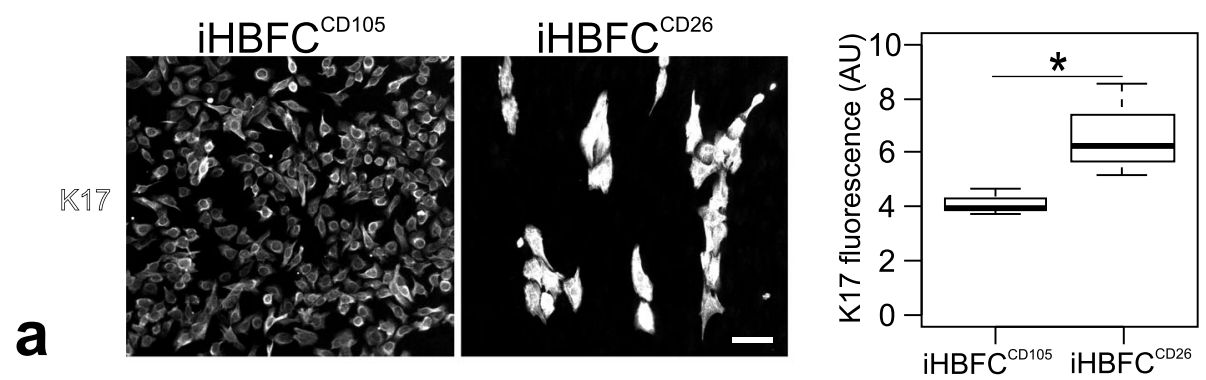

Feeder cells
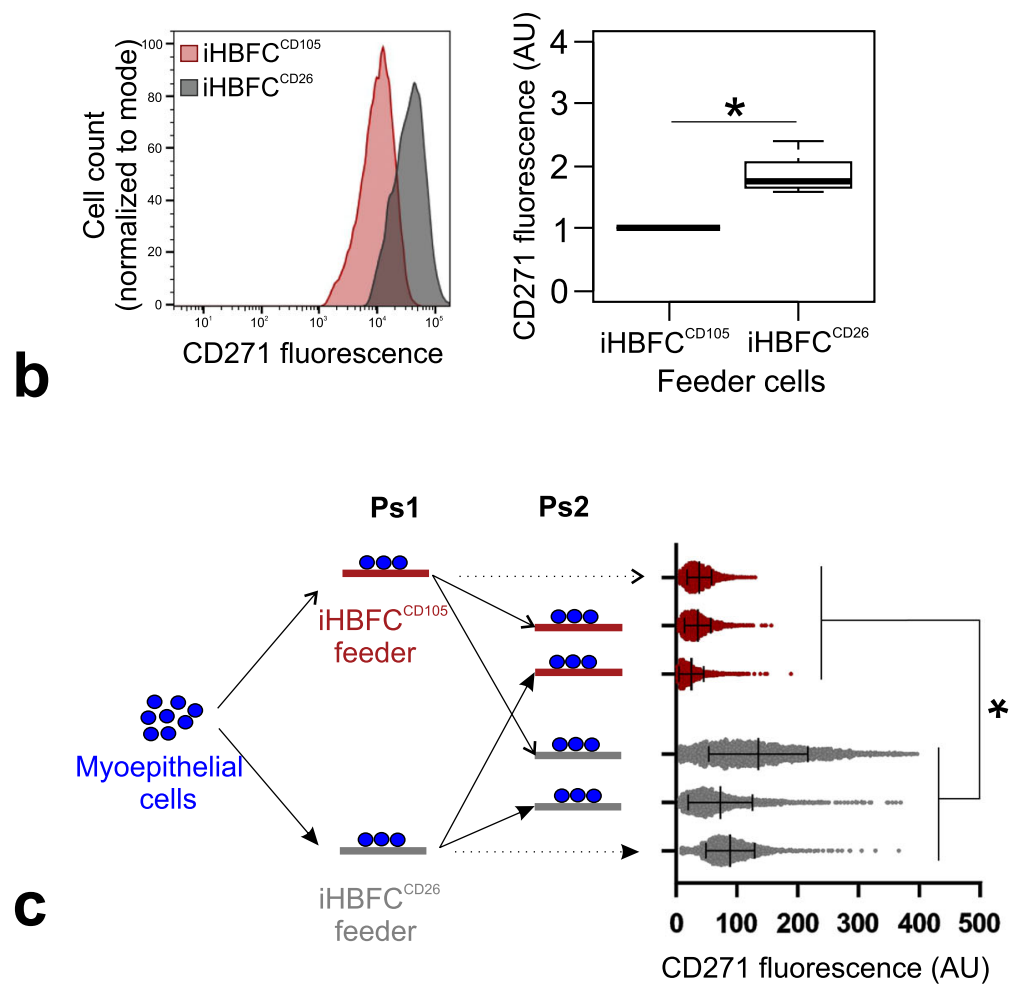

Fig. 4 iHBFC ${ }^{\mathrm{CD} 26}$ convey a ductal-like differentiation of myoepithelial cells. a Images showing FACS sorted CD271 ${ }^{\text {high }} / \mathrm{MUC1}^{\text {low }}$ breast primary myoepithelial cells in CO-culture with $\mathrm{HBFC}^{\mathrm{CD} 105}$ (left) and $\mathrm{HBBCC}^{\mathrm{CD} 26}$ (right), fluorescently labeled for K17 (white) and K14 (not shown) by immunocytochemistry. K14 staining was used as a guide in image analysis to identify K14+ myoepithelial cells prior to measuring myoepithelial K17 staining intensity. Box plot shows interquartile range and median of K17 mean fluorescence in arbitrary units (AU) of three biopsies (whiskers indicate upper and lower quartiles; asterisk indicates significance at $p<0.05$ by Kruskal-Wallis rank-sum test). b Primary myoepithelial/fibroblast cocultures (iHBFC ${ }^{\mathrm{CD} 105}$ (red), iHBFC ${ }^{\mathrm{CD} 26}$ (gray)), were single cell suspended and stained for CD271 before analysis by FACS. Histogram shows cell count normalized to mode versus myoepithelial CD271 staining intensity in arbitrary units (AU) of a single biopsy (left) and box plot shows the interquartile range and median of the mean of CD271 fluorescence intensity relative to iHBFC ${ }^{\mathrm{CD} 105}$ in arbitrary units of three biopsies (right; whiskers indicate upper and lower quartile, asterisk indicates significance at $p<0.05$ by Kruskal-Wallis rank-sum test). c Schematic showing the experimental outline (left): primary $\mathrm{CD} 271^{+}$myoepithelial cells are plated onto confluent fibroblast feeders (passage 1 co-culture, Ps 1), from which myoepithelial cells are isolated and then re-plated onto new fibroblast feeders (passage 2 co-culture, Ps2). Dot plot (right) shows normalized myoepithelial CD271 fluorescence in arbitrary units (AU) with mean values and standard deviations indicated by vertical bars as measured by FACS of 2250 cells in passage 1 and 2 co-cultures grouped according to feeder (iHBFC ${ }^{\mathrm{CD} 105}$ (red) or iHBFC ${ }^{\mathrm{CD} 26}$ (gray)). Note that the myoepithelial phenotype shifts as a consequence of a switch between fibroblasts (asterisk indicates significance at $p<0.05$ by nested $t$ test)

breast. We have previously shown that lobular-derived and ductal-derived epithelial cells maintain their distinct properties either in the absence of fibroblasts, which is in three-dimensional culture within a reconstituted basement membrane, or in co-culture on mouse-derived fibroblasts (3T3-cells) suggesting that epithelial cells are not submitted to modulation by microenvironmental cues $[11,12]$. In the present study, however, we show that early myoepithelial progenitors are susceptible to cues from lobular- and interlobular-like fibroblasts in terms of luminal differentiation repertoire. Thus, if primed on lobular-like fibroblasts, luminal differentiation 


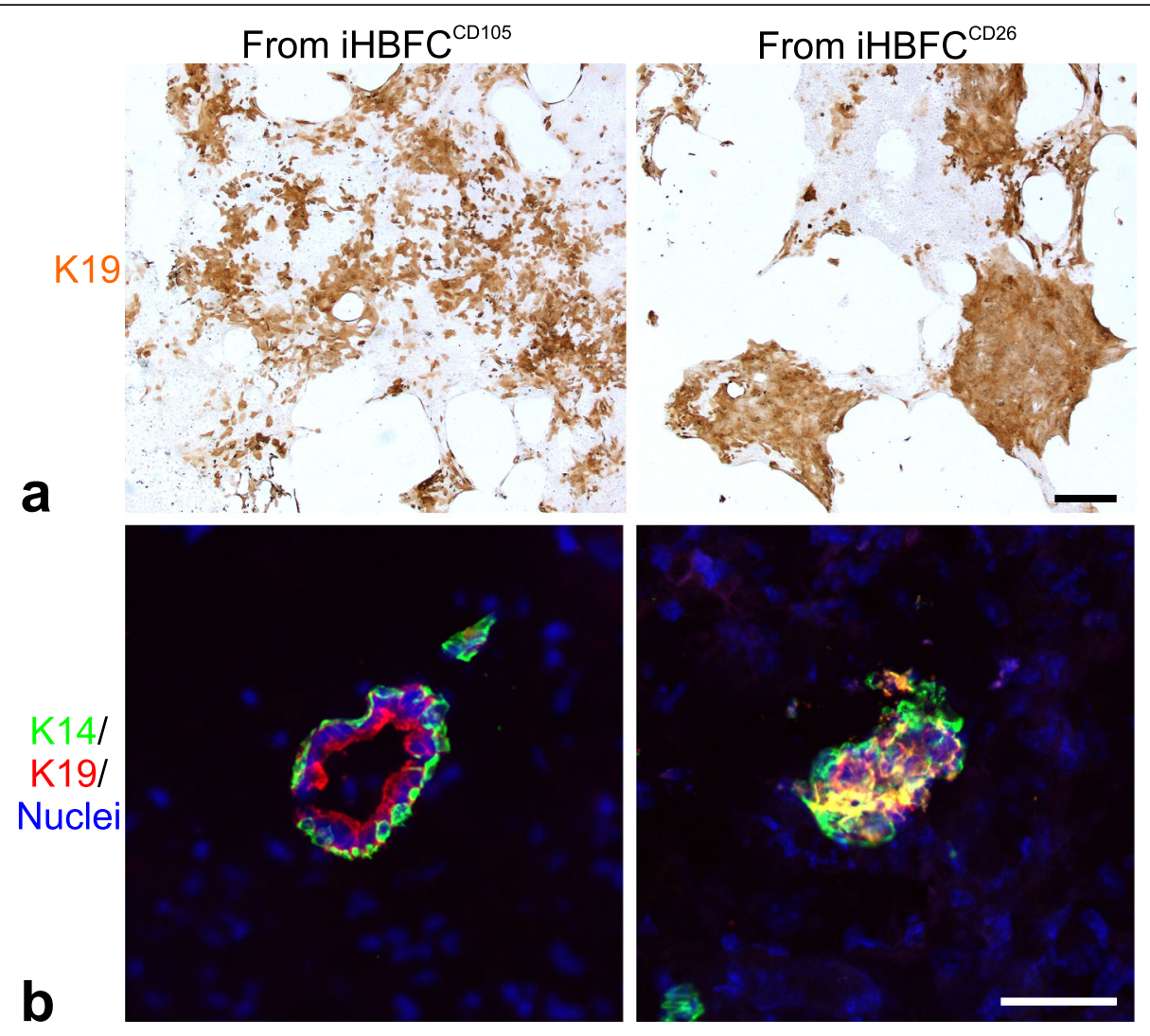

Fig. 5 The luminal differentiation repertoire of myoepithelial progenitors is directed by interaction with specialized fibroblasts. a Comparison of capacity of fibroblasts to direct epithelial progenitor capacity. Myoepithelial cells co-cultured with $\mathrm{iHBFC}^{\mathrm{CD} 105}$ or iHBFC $\mathrm{CD}^{\mathrm{CD} 6}$ were passaged and subjected to luminal differentiation conditions at clonal density and peroxidase stained for K19. While the induced K19 appeared mainly scattered when derived from iHBFC ${ }^{\mathrm{CD} 105}$ co-culture (left), additional rather homogenous islets presented from $\mathrm{HBFCC}^{\mathrm{CD} 26} \mathrm{co}^{-c u l t u r e s}$ (right). The distinct phenotypes were observed in five out of seven tests with absence of homogeneous islets from iHBFC ${ }^{\mathrm{CD} 26}$ in two tests (bar $\left.=500 \mu \mathrm{m}\right)$. $\mathbf{b}$ Representative multicolor confocal images (K19, red; K14, green; nuclei, blue) of cryostat sections of xenografted NOG mice 8 weeks after orthotopic injection of myoepithelial cells from primary co-culture with $\mathrm{iHBFC}{ }^{\mathrm{CD} 105}$ or $\mathrm{HHBFC}^{\mathrm{CD} 26}$. Bilayered epithelial structures were obtained in $6 / 10$ and $5 / 8$ injections from $\mathrm{iHBFC} C^{\mathrm{CD} 105}$ and $\mathrm{HHBFC}^{\mathrm{CD} 26}$, respectively, although at limited numbers, down to a few per transplant. Whereas $\mathrm{iHBFC}^{\mathrm{CD} 105}$ co-culture derived myoepithelial cells readily differentiated into luminal $\mathrm{K} 14^{-/ 10 \mathrm{w}} / \mathrm{K} 19^{+}$cells, co-culture with iHBFC ${ }^{\mathrm{CD} 26}$ resulted mainly in $\mathrm{K} 14^{+} / \mathrm{K} 19^{+}$luminal cells $(\mathrm{bar}=50 \mu \mathrm{m})$

is more elaborate, which is reminiscent of the luminal lineage in TDLUs in situ. On the other hand, if myoepithelial progenitors are primed with interlobular-like fibroblasts, the luminal differentiation is limited to K14 and K19 double-positive progenitors both in culture and in vivo. It is possible that human breast epithelial progenitors for appropriate interaction with the surrounding stroma rely on species-specific crosstalk. This notion is supported by an experimental paradigm described more than a decade ago, when it was shown that normal morphogenesis and differentiation of human breast epithelial cells transplanted into mice required co-implantation with human fibroblasts [49]. Our present findings extend this observation to include plasticity of prospectively isolated human breast progenitors as determined by positional information from resident fibroblasts.

Lobular-like human breast fibroblasts generated either by prospective FACS isolation from primary tissue or through hTERT immortalization exhibit a strong expression of CD105. A number of studies have indicated that CD105 modulates TGF- $\beta$ signaling through ALK5 and responds to bone morphogenic proteins (BMPs) (reviewed in [50]). BMPs also play an important role in maintenance and specification of human breast stem cells [51]. Consistent with this, we found that inhibition of the TGF- $\beta$ signaling cascade by pre-incubation with SB431542 specifically in the lobular-like fibroblasts led to attenuated interaction with epithelial progenitors in the subsequent co-culture experiment. Although still not completely elucidated, it appears that such TGF- $\beta$ dependent epithelial-stromal interaction is crucial also for cancer development. While TGF- $\beta 1$ converts the majority of normal breast fibroblasts to alpha-smooth muscle actin-positive myofibroblasts [15], disrupted TGF- $\beta$-signaling attenuates CAF-induced cancer cell growth [52]. 


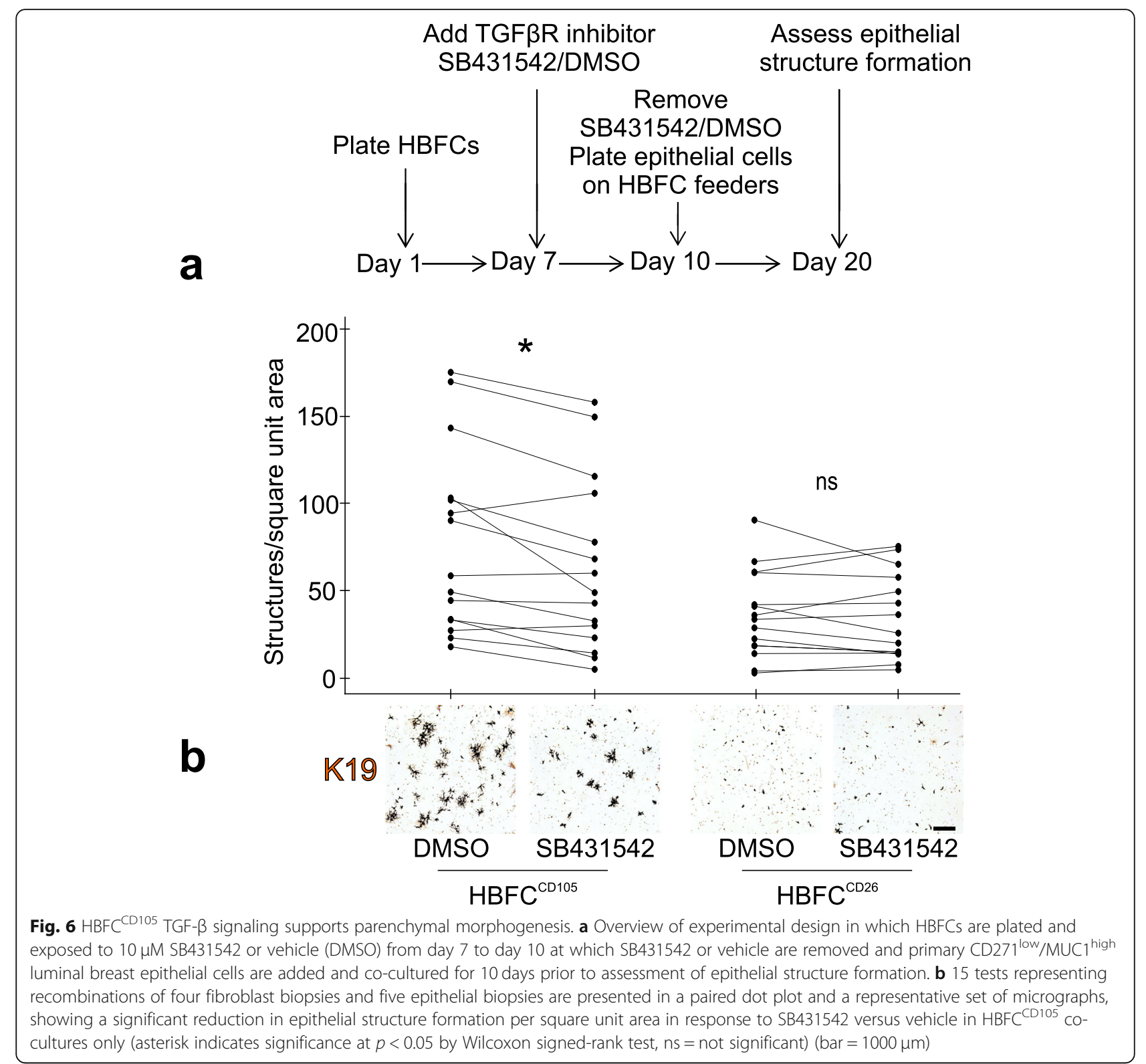

We show here that while lobular-like fibroblasts in many respects are similar to human bone marrowderived MSCs, they fail in an ultimate in vivo test gauging for bone formation. Thus, as far as the human breast is concerned, we can now distinguish resident fibroblasts from bona fide MSCs. This is important because the latter has been implicated in reactive stroma formation such as that occurring in cancer. Thus, it has been speculated that MSCs are recruited to the breast as a source of myofibroblasts or CAFs responsible for important aspects of tumor cell-stroma interaction including promotion of metastasis ([53-55], reviewed in [56]). With the in vivo bone formation assay employed here, the question of a "third" immigrant mesenchymal lineage in breast pathology can be addressed also in a human context. Such investigations are ongoing in our laboratory.

The fibroblast heterogeneity described herein is likely to be in operation in a wider variety of tissues and organs. In the present study, we demonstrate by genome wide gene expression profiling that lobular-like and interlobular-like fibroblasts differ by entire lineage programs with characteristics and functions in common with previously reported papillary and reticular fibroblasts, respectively, in mice and humans [1, 14, 39]. In this regard, it is interesting that $\mathrm{CD} 26^{-}$fibroblasts in mice segregate into mature $\mathrm{CD} 26^{+}$papillary fibroblasts [1] and that in both mice and humans such fibroblasts are responsible for ECM production and in turn fibrosis [57-59]. We propose that the $\mathrm{CD} 26^{+}$interlobular-like 
fibroblasts are responsible for the dense fibrous tissue of the breast and further responsible for the differences in breast density between individuals - a known risk factor for development of breast cancer. This would concur with the observation that another marker, CD36, expressed by lobular fibroblasts, is repressed in high density breast stroma [33]. CD105 ${ }^{+}$lobular-like fibroblasts on the other hand have properties in common with bone marrowderived MSCs and reticular fibroblast progenitors, which participate in wound healing and myofibroblast generation [1]. Previous results from our laboratory have shown that lobular fibroblasts readily generate $\alpha$-smooth muscle actin-positive myofibroblasts [10] and that interlobular fibroblasts exhibit an immune related gene expression profile [10]. Whether the breast cancer repertoire of CAFs is a caricature and maybe even a reminiscence of the normal stromal cell heterogeneity remains an open question. Interestingly, however, recent single-cell RNA sequencing of breast carcinomas has resolved stromal cell diversity to include both myofibroblastic and inflammatory CAFs and not least perivascular cells $[60,61]$. While this concurs with our early studies, which suggested diverse cellular origins of CAFs, including resident fibroblasts and perivascular cells $[62,63]$, our present findings suggest that lineage heterogeneity within the resident fibroblast compartment adds to the complexity. If indeed this is the case and myofibroblast and inflammatory classification operate among both CAFs and normal resident fibroblasts, it is tempting to speculate on lineage interrelationships and how these may be taken advantage of in a clinical setting [64]. The cell lines established in the present study may prove valuable in determining such lineage relationships. It is also a possibility that phenotypic and functional CAF heterogeneity reflects plasticity in a broader sense and in general may be governed more or less by the tumor genotype as suggested in mouse models of pancreatic cancer (reviewed in [65]). In this context, the cell lines may serve to decipher whether a specific tumor genotype instructs development of a particular stromal response independent of recipient initial stromal cell type.

For these reasons, it is likely that both lobular and interlobular-like fibroblasts play important albeit different roles in normal breast as well as in breast cancer.

\section{Conclusions}

Collectively, our study shows that we have established two physiologically relevant, phenotypically distinct human breast fibroblast cell lines, which exhibit specialized functions in maintenance of region-specific characteristics and regulation of neighboring epithelial cells. In the longer perspective, the present developments may provide a basis for the experimentation in cell-based assays to elucidate the earliest events in human breast cancer evolution.

\section{Supplementary information}

Supplementary information accompanies this paper at https://doi.org/10. 1186/s13058-020-01344-0.

Additional file 1: Figure S1. iHBFCs express hTERT. Bar graph depicting the relative hTERT expression in arbitrary units (AU) assessed by RT-qPCR in triplicate normalized to the geometric mean of reference genes GAPD H, HPRT1 and PGK1. hTERT expression was detected in cells transduced with hTERT (iHBFC ${ }^{C D 105}$ and $\mathrm{HHBFC}^{\mathrm{CD} 26}$ ) but not in cells transduced with the empty vector (evHBFC ${ }^{\mathrm{CD} 105}$ and evHBFC ${ }^{\mathrm{CD} 26}$ ). Error bars represent mean \pm SD.

Additional file 2: Figure S2. $\mathrm{HHBFC}^{\mathrm{CD} 105}$ are MSC-like but lack in vivo osteogenic differentiation potential. $(a, b)$ Comparison of the potential of $\mathrm{iHBFC}^{\mathrm{CD} 105}$ and $\mathrm{HHBFC}^{\mathrm{CD} 26}$ cells to undergo adipogenic and osteogenic differentiation. (a) Micrographs of cells exposed to adipogenic inducing conditions followed by staining with Oil Red $\mathrm{O}$ and hematoxylin. Prominent perinuclear accumulation of lipid droplets is seen in $\mathrm{HHBCC}^{\mathrm{CD} 105}$ cells only (left). The stainings are representative of five independent experiments with cells in up to passage 50, (bar $=50 \mu \mathrm{m}$ ). (b) Quantification of matrix mineralization upon exposure to standard medium (-) or osteogenic inducing medium $(\mathrm{OIM} ;+)$ followed by staining with alizarin red. Significant matrix mineralization is restricted to iHBFC ${ }^{\mathrm{CD} 105}$ (left; asterisk indicates $p<0.05$ tested by one-way Anova with Tukey's honest significance test). Matrix mineralization was repeatedly tested positive in $\mathrm{iHBFC}^{\mathrm{CD} 105}$ in up to passage 50. Bars represent the mean of three independent experiments \pm SD. AU: arbitrary units. (c) iHBFC ${ }^{\mathrm{CD} 105}$ and hMSCTERT cells were mixed with hydroxyapatite/tricalcium and implanted subcutaneously into immunodeficient mice. Implants were removed after eight weeks, processed for staining by human specific vimentin (top row, brown) and hematoxylin/eosin (H\&E, bottom row). Positive humanspecific vimentin staining indicates presence of the implanted cells. White dotted outlines indicate normal lamellar bone formed by hMSC-TERT, which is absent in iHBFC ${ }^{\mathrm{CD} 105}$ transplants, (bar $\left.=50 \mu \mathrm{m}\right)$.

Additional file 3: Figure S3. Myoepithelial CD271 expression is higher in ducts than in TDLUs. (a) Representative images of normal breast cryostat sections stained by immunofluorescence for a-smooth muscle actin (a-SMA, green, top panel) and CD271 (green, bottom panel) and nuclei counterstained with DAPI (blue) ( $n=3$ biopsies). Positive staining for a-SMA reveals myoepithelial cells in both TDLUs (left) and ducts (right). In three out of three biopsies, the myoepithelium in ducts exhibited more intense staining for CD271 relative to the myoepithelium in TDLUs. (b) Representative FACS diagram of a trypsinized breast organoid preparation stained by CD271 and CD326 from which CD271 ${ }^{\text {high }}$ and CD271 low myoepithelial cells were isolated (gates indicated by circles), smeared and stained by immunofluorescence for K17 (green) and nuclei (blue). (c) Histogram showing enrichment in percent of $\mathrm{K} 7^{+}$cells among CD271 $1^{\text {high }}$ versus CD271 ${ }^{\text {low }}$ myoepithelial cells in four out of four biopsies, (bar $=50 \mu \mathrm{m})$

Additional file 4: Figure S4. Disruption of TGF- $\beta$ signaling decreases epithelial morphogenesis in $\mathrm{HBFC}^{\mathrm{CD} 105}$ co-cultures. Primary CD271 low/ MUC $1^{\text {high }}$ luminal epithelial cells from two different biopsies were plated onto confluent fibroblasts feeders and the resulting co-cultures were exposed to $10 \mu \mathrm{M}$ SB431542 or vehicle (DMSO) from day 2 after epithelial plating. At day 9 the number of structures per square unit area was assessed as illustrated in Fig. 3. While the number of epithelial structures on HBFC ${ }^{\mathrm{CD} 105}$ is reduced by SB431542, the capacity of HBFC ${ }^{\mathrm{CD} 26}$ to influence epithelial morphogenesis apparently is not affected by the TGF- $\beta$ signaling inhibitor.

\section{Abbreviations}

CAF: Carcinoma-associated fibroblast; CD: Cluster of differentiation; FACS: Fluorescence-activated cell sorting; hTERT: Human telomerase reverse transcriptase; iHBFC: Immortalized human breast fibroblastic cell; MSC: Mesenchymal stem cell; MUC1: Mucin 1; TDLU: Terminal duct lobular unit; TGF- $\beta$ : Transforming growth factor-beta

\section{Acknowledgements}

We thank Lena Kristensen, Tove Marianne Lund, Anita Sharma Friismose, and Lone Christensen for expert technical assistance and Nicholas Ditzel for help 
with in vivo bone formation. The donors, Benedikte Thuesen and Trine Foged Henriksen, Capio CFR Hospitaler, are acknowledged for providing breast biopsy material. The Core Facility for Integrated Microscopy (University of Copenhagen) is acknowledged for confocal microscope accessibility.

\section{Authors' contributions}

M. M., O. W. P., and L. R.J. designed the research; M. M., J. K., R. V., N. G., and A. J. performed the research; M. K., O. W. P., and L. R.-J. supervised the study; M. M., J. K., R. V., O. W. P., and L. R.-J. contributed new reagents/analytic tools; M. M., J. K., R. V., N. G., A. J., M. K., O. W. P., and L. R.-J. analyzed the data; M. M., O. W. P., and L. R.-J. wrote the paper; M. M., J. K., R. V., N. G., A. J., M. K., O. W. P., and L. R.-J. reviewed and edited the paper. The authors read and approved the final manuscript.

\section{Funding}

This work was supported by Novo Nordisk Fonden (NNF17CC0027852) and Danish Research Council grant 10-092798 (to DanStem), Toyota-Fonden Denmark and Anita og Tage Therkelsens Fond (to R.V.), Familien Erichsens Mindefond and Vera og Carl Johan Michaelsens Legat (to J.K.), Harboefonden, Else og Mogens Wedell-wedellborgs Fond, Danish Cancer Society Grant R146-A9257 and Dagmar Marshalls Fond (to L.R.-J.), Novo Nordisk Fonden (NNF18CC0033666 (to N.G.), the Kirsten and Freddy Johansens Fond (to O.W.P).

\section{Availability of data and materials}

The RNA sequencing dataset comparing lobular and interlobular fibroblasts generated and analyzed during the current study is available in the Gene Expression Omnibus (GEO) repository, [GEO accession number GSE153646, https://www.ncbi.nlm.nih.gov/geo/query/acc.cgi?acc=GSE153646].

\section{Ethics approval and consent to participate}

The Regional Scientific Ethical Committees (Region Hovedstaden, H-2-2011052) and the Danish Data Protection Agency (2011-41-6722) reviewed and approved the use and storage of human material. The procedures for transplantation of human cells to mice were approved by the Danish National Animal Experiment Inspectorate (2017-15-0201-01315 and 2017-15-020101210).

\section{Consent for publication}

Not applicable.

\section{Competing interests}

The authors declare that they have no competing interests.

\section{Author details}

${ }^{1}$ Department of Cellular and Molecular Medicine, University of Copenhagen, Copenhagen, Denmark. ${ }^{2}$ Danish Stem Cell Centre, University of Copenhagen, Copenhagen, Denmark. ${ }^{3}$ Present Address: Division of Translational Cancer Research, Department of Laboratory Medicine, Lund University, Lund, Sweden. ${ }^{4}$ Laboratory of Molecular Endocrinology, KMEB, Department of Endocrinology, Odense University Hospital and University of Southern Denmark, Odense, Denmark. ${ }^{5}$ Section for Cell Biology and Physiology, Department of Biology, University of Copenhagen, Copenhagen, Denmark.

Received: 30 June 2020 Accepted: 16 September 2020 Published online: 29 September 2020

\section{References}

1. Driskell RR, Lichtenberger BM, Hoste E, Kretzschmar K, Simons BD, Charalambous M, Ferrori SR, Herault Y, Pavlovic G, Ferguson-Smith AC, et al. Distinct fibroblast lineages determine dermal architecture in skin development and repair. Nature. 2013;504:277-81.

2. Chen $X$, Song E. Turning foes to friends: targeting cancer-associated fibroblasts. Nature Rev Drug Discov. 2019;18:99-115.

3. Tlsty TD, Gascard P. Stromal directives can control cancer. Science. 2019:365:122-3.

4. Wellings SR, Jensen HM, Marcum RG. An atlas of subgross pathology of the human breast with special reference to possible precancerous lesions. J Natl Cancer Inst. 1975;55:231-73.

5. Cardiff RD, Wellings SR. The comparative pathology of human and mouse mammary glands. J Mammary Gland Biol Neoplasia. 1999;4(1):105-22.
6. Russo J, Russo IH. Development of the human breast. Maturitas. 2004; 49(1):2-15.

7. Atherton AJ, Warburton MJ, O'Hare MJ, Monaghan P, Schuppan D, Gusterson BA. Differential expression of type XIV collagen/undulin by human mammary gland intralobular and interlobular fibroblasts. Cell Tissue Res. 1998:291(3):507-11.

8. Atherton AJ, O'Hare MJ, Buluwela L, Titley J, Monaghan P, Paterson HF, Warburton MJ, Gusterson BA. Ectoenzyme regulation by phenotypically distinct fibroblast sub-populations isolated from the human mammary gland. J Cell Sci. 1994;107:2931-9.

9. Fleming JM, Long E, Ginsburg E, Gerscovich D, Meltzer PS, Vonderhaar BK. Interlobular and intralobular mammary stroma: genotype may not reflect phenotype. BMC Cell Biol. 2008;9:46-56.

10. Morsing M, Klitgaard MC, Jafari A, Villadsen R, Kassem M, Petersen OW, Rønnov-Jessen L. Evidence of two distinct functionally specialized fibroblast lineages in breast stroma. Breast Cancer Res. 2016;18:108-17.

11. Fridriksdottir AJ, Villadsen R, Morsing M, Klitgaard MC, Kim J, Petersen OW, Rønnov-Jessen L. Proof of region-specific multipotent progenitors in human breast epithelia. Proc Natl Acad Sci U S A. 2017;6:E10102-11.

12. Villadsen R, Fridriksdottir AJ, Rønnov-Jessen L, Gudjonsson T, Rank F, LaBarge MA, Bissell MJ, Petersen OW. Evidence of a stem cell hierarchy in the adult human breast. J Cell Biol. 2007;177:87-101.

13. Honeth G, Lombardi S, Ginestier C, Hur M, Marlow R, Buchupalli B, Shinomiya I, Gaxinska P, Bombelli S, Ramalingam V, et al. Aldehyde dehydrogenase and estrogen receptor define a hierarchy of cellular differentiation in the normal human mammary epithelium. Breast Cancer Res. 2014;16:R52.

14. Philippeos C, Telerman SB, Oulés B, Pisco AO, Shaw TJ, Elgueta R, Lombardi $\mathrm{G}$, Driskell RR, Soldin M, Lynch MD, et al. Spatial and single-cell transcriptional profiling identifies functionally distinct human dermal fibroblast subpopulations. J Invest Dermatol. 2018;138:811-25.

15. Rønnov-Jessen $L$, Petersen OW. Induction of a-smooth muscle actin by transforming growth factor- $\beta 1$ in quiescent human breast gland fibroblasts. Implications for myofibroblast generation in breast neoplasia. Lab Investig. 1993;68:696-707.

16. Simonsen JL, Rosada C, Serakinci N, Justesen J, Stenderup K, Rattan SIS, Jensen TG, Kassem M. Telomerase expression extends the proliferative lifespan and maintains the osteogenic potential of human bone marrow stromal cells. Nat Biotechnol. 2002;20:592-6.

17. Counter CM, Hahn WC, Wei W, Caddle SD, Beijersbergen RL, Lansdorp PM, Sedivy JM, Weinberg RA. Dissociation among in vitro telomerase activity, telomere maintenance, and cellular immortalization. Proc Natl Acad Sci U S A. 1998:95(25):14723-8.

18. Morgenstern JP, Land $\mathrm{H}$. Advanced mammalian gene transfer: high titre retroviral vectors with multiple drug selection markers and a complementary helper-free packaging cell line. Nucleic Acids Res. 1990; 18:3587-96.

19. Naviaux RK, Costanzi E, Haas M, Verma IM. The $\mathrm{pCL}$ vector system: rapid production of helper-free high titer, recombinant retroviruses. J Virol. 1996; 70:5701-5.

20. Hines WC, Yaswen P, Bissell MJ. Modelling breast cancer requires identification and correction of a critical cell lineage- dependent transduction bias. Nat Commun. 2015:6:6927-37.

21. Langmead B, Salzberg SL. Fast grapped-read alignment with Bowtie 2. Nat Methods. 2012;9:357-8.

22. Li B, Dewey CN. RSEM: accurate transcript quantification from RNA-Seq data with or without reference genome. BMC Bioinformatics. 2011;12:323-38.

23. Love M, Huber W, Anders S. Moderated estimation of fold change and dispersion for RNA-seq data with DESeq2. Genome Biol. 2014;15:550-70.

24. Jafari A, Siersbaek MS, Chen L, Qanie D, Zaher W, Abdallah BM, Kassem M. Pharmacological inhibition of protein kinase G1 enhances bone formation by human skeletal stem cells through activation of RhoA-Aky signaling. Stem Cells. 2015:33:2219-31.

25. Qiu W, Hu Y, Andersen TE, Jafari A, Li N, Chen W, Kassem M. Tumor necrosis factor receptor superfamily member 19 (TNFRSR19) regulates differentiation fate of human mesenchymal (stromal) stem cellsthrough canonical Wnt signaling and C/EBP. J Biol Chem. 2010;285:14438-49.

26. Jafari A, Isa A, Chen L, Ditzel N, Zaher W, Harkness L, Johnsen HE, Abdallah BM, Clausen C, Kassem M. TAFA2 induces skeletal (stromal) stem cell migration through activation of Rac1-p38 signaling. Stem Cells. 2019;37:407-16 
27. Petersen OW, van Deurs B. Preservation of defined phenotypic traits in short-time cultured human breast carcinoma derived epithelial cells. Cancer Res. 1987:47:856-66.

28. Rønnov-Jessen L, Celis JE, van Deurs B, Petersen OW. A fibroblast-associated antigen: characterization in fibroblasts and immunoreactivity in smooth muscle differentiated stromal cells. J Histochem Cytochem. 1992;40:475-86.

29. Jafari A, Qanie D, Andersen TE, Zhang Y, Chen L, Postert B, Parsons S, Ditzel $\mathrm{N}$, Khosla S, Thidemann Johansen $\mathrm{H}$, et al. Legumain regulates differentiation fate of human bone marrow stromal cells and is altered in postmenopausal osteoporosis. Stem Cell Rep. 2017;8:373-86.

30. Mahmood A, Harkness L, Abdallah BM, Elsafadi M, Al-Nbaheen MS, Aldahmash A, Kassem M. Derivation of stromal (skeletal and mesenchymal) stem-like cells from human embryonic stem cells. Stem Cells Dev. 2012;21:3114-24.

31. Harkness L, Zaher W, Ditzel N, Isa A, Kassem M. CD146/MCAM defines functionality of human bone marrow stromal stem cell populations. Stem Cell Res Ther. 2016;7:4. https://doi.org/10.1186/s13287-015-0266-z. PMID: 26753846; PMCID: PMC4710006.

32. MacFadyen JR, Haworth $\mathrm{O}$, Robertson D, Hardie D, Webster M-T, Morris HR, Panico M, Sutton-Smith M, Dell A, van der Geer P, et al. Endosialin (TEM1, CD248) is a marker of stromal fibroblasts and is not selectively expressed on tumour endothelium. FEBS Lett. 2005:579:2569-75.

33. DeFilippis RA, Chang H, Dumont N, Rabban JT, Chen Y-Y, Fontenay GV, Berman HK, Gauthier ML, Zhao J, Hu D, et al. CD36 repression activated a multicellular stromal program shared by high mammagraphic density and tumor tissues. Cancer Discov. 2012;2:826-39.

34. Chauhan $\mathrm{H}$, Abraham A, Phillips JR, Pringle $J H$, Walker RA, Jones JL. There is more than one kind of myofibroblast: analysis of CD34 expression in benign, in situ, and invasive breast lesions. J Clin Pathol. 2003;56(4):271-6.

35. Sugimoto $H$, Mundel TM, Kieran MW, Kalluri R. Identification of fibroblast heterogeneity in the tumor microenvironment. Cancer Biol Ther. 2006;5:1640-6.

36. Stanley MJ, Stanley MW, Sanderson RD, Zera R. Syndecan-1 expression is induced in the stroma of infiltrating breast carcinoma. Am J Clin Pathol. 1999;112:377-83.

37. Jiang D, Rinkevich Y. Defining skin fibroblastic cell types beyond CD90 Front Cell Dev Biol. 2018;6:133.

38. Atherton AJ, Monaghan P, Warburton MJ, Robertson D, Kenny AJ, Gusterson BA. Dipeptidyl peptidase IV expression identifies a functional sub-population of breast fibroblasts. Int J Cancer. 1992:50:15-9.

39. Korosec A, Frech S, Gesslbauer B, Vierhapper M, Radtke C, Petzelbauer P, Lichtenberger BM. Lineage identity and location within the dermis determine the function of papillary and reticular fibroblasts in human skin. J Invest Dermatol. 2019;139:342-51.

40. Hopkinson BM, Klitgaard MC, Petersen OW, Villadsen R, Rønnov-Jessen L, Kim J. Establishment of a normal-derived estrogen receptor-positive cell line comparable to the prevailing human breast cancer subtype. Oncotarget. 2017:8:1-14.

41. Eirew P, Stingl J, Raouf A, Turashvili G, Aparicio S, Emerman JT, Eaves CJ. A method for quantifying normal human mammary epithelial stem cells with in vivo regenerative ability. Nat Med. 2008;14:1384-9.

42. Lim E, Vaillant F, Wu D, Forrest NC, Pal B, Hart AH, Asselin-Labat ML, Gyorki DE, Ward T, Partanen A, et al. Aberrant luminal progenitors as the candidate target population for basal tumor development in BRCA1 mutation carriers. Nat Med. 2009;15:907-15.

43. Prater MD, Petit V, Russell IA, Giraddi RR, Shehata M, Menon S, Schulte R, Kalajzic I, Rath N, Olson ME, et al. Mammary stem cells have myoepithelial cell properties. Nat Cell Biol. 2014;16:942-50.

44. Pérez-Gómez E, del Castillo G, Santibáñez JF, López-Novoa JM, Bernabéu C, Quintanilla M. The role of TGF- $\beta$ coreceptor endoglin in cancer. Sci World J. 2010;10:2367-84

45. Mardomi A, Sabzichi M, Hussein Somi M, Shanehbandi D, Rahbarghazi R, Taj Sanjarani O, Samadi N. Trafficking mechanism of bone marrow-derived mesenchymal stem cells toward hepatacellular carcinoma HepG2 cells by modulating Endoglin, CXCR4 and TGF- $\beta$. Cell Mol Biol. 2016:62:81-6.

46. Roberts KJ, Kershner AM, Beachy PA. The stromal niche for epithelial stem cells: a template for regeneration and a brake on malignancy. Cancer Cell. 2017;32:404-10.

47. Chang HY, Chi J-T, Dudoit S, Bondre C, Van de Rijn M, Botstein D, Brown PO. Diversity, topographic differentiation, and positional memory in human fibroblasts. Proc Natl Acad Sci U S A. 2002;99:12877-82.

48. Rinn JL, Bondre C, Gladstone HB, Brown PO, Chang HY. Anatomic demarcation by positional variation in fibroblast gene expression programs. PLoS Genet. 2006;2:1084-96.
49. Kuperwasser C, Chavarria T, Wu M, Magrane G, Gray JW, Carey L, Richardson A, Weinberg RA. Reconstruction of functionally normal and malignant human breast tissues in mice. Proc Natl Acad Sci U S A. 2004;101(14):4966-71.

50. Valluru M, Staton CA, Reed MWR, Brown NJ. Transforming growth factor- $\beta$ and endoglin signaling orchestrate wound healing. Front Physiol. 2011;2:1-12.

51. Chapellier M, Bachelard-Cascales E, Schmidt X, Clément F, Treilleux I, Delay E, Jammot A, Ménétrier-Caux C, Pochon G, Besancon R, et al. Disequilibrium of BMP2 levels in the breast stem cell niche launches epithelial transformation by overamplifying BMPRIB cell response. Stem Cell Rep. 2015;4:239-54.

52. Takai K, Le A, Weaver VM, Werb Z. Targeting the cancer-associated fibroblasts as a treatment in triple-negative breast cancer. Oncotarget. 2016; 7:82889-901.

53. Karnoub AE, Dash AB, Vo AP, Sullivan A, Brooks MW, Bell GW, Richardson AL, Polyak K, Tubo R, Weinberg RA. Mesenchymal stem cells within tumour stroma promote breast cancer metastasis. Nature. 2007:449:557-65.

54. Goldstein RH, Reagan MR, Anderson K, Kaplan DL, Rosenblatt M. Human bone marrow-derived MSCs can home to orthotopic breast cancer tumors and promote bone metastasis. Cancer Res. 2010;70:10044-50.

55. Mishra PJ, Mishra PJ, Humeniuk R, Medina DJ, Alexe G, Mesirov JP, Ganesan S, Glod JW, Banerjee D. Carcinoma-associated fibroblast-like differentiation of human mesenchymal stem cells. Cancer Res. 2008:68:4331-49.

56. Chan T-S, Shaked Y, Tsai KK. Targeting the interplay between cancer fibroblasts, mesenchymal stem cells, and cancer stem cells in desmoplastic cancers. Front Oncol. 2019;9:1-15.

57. Rinkevich Y, Walmsley GG, Hu MS, Maan ZN, Newman AM, Drukker M Januszyk M, Krampitz GW, Gurtner GC, Lorenz HP, Weissman IL, Longaker MT. Skin fibrosis. Identification and isolation of a dermal lineage with intrinsic fibrogenic potential. Science. 2015;348(6232):aaa2151. https://doi. org/10.1126/science.aaa2151. PMID: 25883361; PMCID: PMC5088503.

58. Mah W, Jiang G, Olver D, Gallant-Behm C, Wiebe C, Hart DA, Koivisto L, Larjava H, Häkkinen L. Elevated CD26 Expression by Skin Fibroblasts Distinguishes a Profibrotic Phenotype Involved in Scar Formation Compared to Gingival Fibroblasts. Am J Pathol. 2017;187(8):1717-35. https://doi.org/10. 1016/j.ajpath.2017.04.017. Epub 2017 Jun 20. PMID: 28641076.

59. Borrelli MR, Irizzary D, Patel RA, Nguyen D, Momeni A, Longaker MT, Wan DC. Pro-Fibrotic CD26-positive fibroblasts are present in greater abundance in breast capsule tissue of irradiated breasts. Aesthet Surg J. 2020;40(4):36979. https://doi.org/10.1093/asj/sjz109. PMID: 30972420; PMCID: PMC7317086.

60. Kieffer Y, Hocine HR, Gentric G, Pelon F, Bernard C, Bourachot B, Lameiras S, Albergante L, Bonneau C, Guyard A, Tarte K, Zinovyev A, Baulande S, Zalcman G, Vincent-Salomon A, Mechta-Grigoriou F. Single-cell analysis reveals fibroblast clusters linked to immunotherapy resistance in cancer. Cancer Discov. 2020;10(9):1330-51. https://doi.org/10.1158/2159-8290.CD-191384. Epub 2020 May 20. PMID: 32434947

61. Wu SZ, Roden DL, Wang C, Holliday H, Harvey K, Cazet AS, Murphy KJ, Pereira B, Al-Eryani G, Bartonicek N, Hou R, Torpy JR, Junankar S, Chan CL, Lam CE, Hui MN, Gluch L, Beith J, Parker A, Robbins E, Segara D, Mak C, Cooper C, Warrier S, Forrest A, Powell J, O'Toole S, Cox TR, Timpson P, Lim E, Liu XS, Swarbrick A. Stromal cell diversity associated with immune evasion in human triple-negative breast cancer. EMBO J. 2020:e104063. https://doi.org/10.15252/embj.2019104063.

62. Rønnov-Jessen L, van Deurs B, Nielsen M, Petersen OW. Identification, paracrine generation and possible function of human breast carcinoma myofibroblasts in culture. In Vitro Cell Dev Biol. 1992;28A:273-83.

63. Rønnov-Jessen L, Petersen OW, Koteliansky VE, Bissell MJ. The origin of the myofibroblasts in breast cancer: recapitulation of tumor environment in culture unravels diversity and implicates converted fibroblasts and recruited smooth muscle cells. J Clin Invest. 1995:95:859-73.

64. Mezawa Y, Daigo Y, Takano A, Miyago Y, Yokose T, Yamashita T, Morimoto C, Hino O. CD26 expression is attenuated by TGF- $\beta$ and SDF-1 autocrine signaling on stromal myofibroblasts in human breast cancers. Cancer Med. 2019;8:3936-48.

65. Pereira BA, Vennin C, Papanicolaou M, Chambers CR, Herrmann D, Morton JP, Cox TR, Timpson P. CAF subpopulations: a new reservoir of stromal targets in pancreatic cancer. Trends Cancer. 2019;5:1-18.

\section{Publisher's Note}

Springer Nature remains neutral with regard to jurisdictional claims in published maps and institutional affiliations. 